\title{
(Phospho)lipid-based Nanosystems for Skin Administration
}

\author{
Željka Vanić1, Ann-Mari Holsæter ${ }^{2}$ and Nataša Škalko-Basnet ${ }^{2}$,* \\ ${ }^{1}$ Department of Pharmaceutical Technology, Faculty of Pharmacy and Biochemistry, University \\ of Zagreb, A. Kovačića 1, 10000 Zagreb, Croatia \\ ${ }^{2}$ Drug Transport and Delivery Research Group, Department of Pharmacy, Faculty of Health \\ Sciences, University of Troms $\emptyset$ The Arctic University of Norway, Universitetsveien 57, 9037 \\ Troms $\emptyset$, Norway \\ * Address correspondence to this author at Drug Transport and Delivery Research Group, \\ Department of Pharmacy, Faculty of Health Sciences, University of Troms $\varnothing$ The Arctic \\ University of Norway, Universitetsveien 57, 9037 Troms $\varnothing$, Norway; Telephone: +4777646640 ; \\ Fax: +4777646151; Email: Natasa.skalko-basnet@uit.no
}

Formatted: Norwegian (Bokmål)

\section{Running title: Nanosystems and skin}

Keywords: skin, drug delivery nanosystems, nanopharmaceuticals, nanotechnology, skin therapy 


\begin{abstract}
Nanotechnology and nanomedicine provide a platform for advanced therapeutic strategies for dermal and transdermal drug delivery. The focus of this review is on the current state-of-art in lipid-based nanotechnology and nanomedicine for (trans)dermal drug therapy. Drug delivery nanosystems based on the (phospho)lipid constituents are characterized and compared, with the emphasis on their ability to assure the controlled drug release to the skin and skin appendages, drug targeting and safety. Different types of liposomes, biphasic vesicles, particulate lipid-based nanosystems and micro- and nano-emulsions are discussed in more details. Extensive research in preclinical studies has shown that numerous parameters including the composition, size, surface properties and their combinations affect the deposition and/or penetration of carrier-associated drug into/through the skin, and consequently determine the therapeutic effect. The superiority of the most promising nanopharmaceuticals has been confirmed in clinical studies. We have selected several common skin disorders and provided overview over promises of nanodermatology in antimicrobial skin therapy, anti-acne treatment, skin oncology, gene delivery and vaccines. We addressed the potential toxicity and irritation issues and provided an overview of registered lipid-based products
\end{abstract}

Key words: skin, drug delivery nanosystems, nanopharmaceuticals, nanotechnology, skin therapy

\title{
(Graphical abstract)
}




\section{INTRODUCTION}

The skin conditions were reported to be the fourth leading cause of nonfatal disease burden at the global level. The skin disease prevention and treatment are to be included in the global health strategies of the future [1]. In parallel, recent trends in the pharmaceutical development of topical drug products are moving from a search for a new chemical entity towards development of new drug products based on the already approved drugs [2]. Nanotechnology, one of the fastest progressing fields in various research arenas, can enable development of superior drug products and is often seen as an intelligent design to treat complex diseases based on the inbuilt ability to perform temporal and spatial site-specific delivery [3-5].

Nanodermatology, nanotechnology applied to dermatology, represents one of the most advanced fields both from the scientific as well as economic point of view. Nanodermatology offers novel directions in the medical diagnosis, monitoring and treatment of skin diseases [6]. These emerging drug delivery technologies that often involve self-assembled phospholipid-based vesicular carriers (liposomes, ethosomes), particulate carriers (lipid nanoparticles), emulsionbased nanosystems (micro- and nano-emulsions) and similar and are in the focus of this review. We attempted to provide an unbiased overview of these nanosystems and comment on their advantages and limitations. Due to a limited space, we could not cite all of the reported findings and tried to cite the representative articles reporting the original delivery systems, those including mechanistic studies and in vivo data. Similarly, we could not include the nanocosmeceuticals destined for skin administration. This review encompasses all the lipid-based nanosystems (vesicular, particular, emulsion-based) intended for either topical skin delivery (dermal) or systemic (transdermal) delivery of drugs and provides the state-of-the art in the field. 


\section{BARRIERS FOR SKIN DELIVERY}

Numerous reviews have characterized the skin anatomy and physiology and the readers are referred to for example Bouwstra and Ponec [7], Prow and colleagues [8] and Banarjee [9].

The barrier property of the skin is the synergy between the positive cooperation and interactions between stratum corneum macro and micro-structure, bi- and three-dimensional supramolecular organization of the lipid matrix and the whole composition of stratum corneum [10]. The macrostructure represents corneocytes cross-sectional organization often simplified as a "brick and mortar" model [11]. The microstructure refers to supramolecular organization of the intercorneocyte lipids [7]. Non-uniform cellular packing of stratum corneum representing the permeability barrier of intact skin was confirmed by Schätzlein and Cevc [12]. The surface of the healthy stratum corneum is of slightly acidic $\mathrm{pH}$. $\mathrm{pH}$ gradient increases up to the central layers of the stratum corneum where the $\mathrm{pH}$ reaches the values identical to that in viable epidermis [11]. It is expected that lipid-based nanopharmaceuticals may, to a different extent, interact with the skin lipids, presumably through the fusion and mixing [13]. Their composition and physicochemical properties may enhance or limit the ingress and diffusion of drug into/through the skin [10]. The sweat glands and pilosebaceous units open on the skin surface representing the potential penetration pathway for nanosystems. However, the low density of those appendages and intrinsic epithelization should be taken into the consideration [11].

The hydration and/or occlusion of stratum corneum will reduce the barrier properties and assist in the penetration. When water saturates the skin its permeability significantly increases. Hydration may result from water diffusing from underlying epidermal layers or from perspiration that accumulates after the application of an occlusive vehicle or dressing [14]. These effects can be 
achieved by the proper choice of nanosystem as well as a vehicle (base) often applied to improve the viscosity and achieve applications properties of liquid nanosystems [15-17]The interactions between the vehicle (nanosystem and/or base), skin and drug affect the release of the drug, its penetration through the stratum corneum, permeation through the skin layers leading to drug deposition (dermal delivery) or absorption into the blood (transdermal delivery). Release of the drug from the vehicle and uptake into the stratum corneum is dependent on the relative solubility in each skin layer and hence, the stratum corneum-vehicle partition coefficient. The diffusion coefficient (speed at which the drug moves within each skin layer) is dependent on the drug properties including the molecular weight, solubility, melting point, ionization and potential for binding within the environment (epidermal layers). General rule is that drugs less than $500 \mathrm{Da}$, with low melting point and those having $\log$ P of 2-3 can permeate via both the lipid and polar microenvironments within the intercellular route and are good candidate for (trans)dermal delivery [14].

The effects of the nanosystem and base on the skin penetration of the drug are described in more details in the very recent review by our group [18].

\section{NANODERMATOLOGY}

In respect to the skin and wound therapy, the potential of nanopharmaceuticals in treating local skin and systemic diseases has yet to be fully realized, however the extensive research efforts are expected to result in improved therapy outcome [19,20]. Nanosized delivery systems offer an opportunity for extensive innovation in nanomedicine, making them an attractive target in drug product development. For more details on the skin properties relevant for the interaction between nanoparticles and skin the readers are referred to the extensive review published by Prow and 
colleagues [8]. Nanosized drug delivery systems designed for improved skin therapy are expected to exhibit all or at least some of the desired features, namely to be able to protect drug from degradation as well as improve penetration of drug into/through the skin [3]. The limitations in the analytical tools and instrument sensitivity to detect nanoparticles, together with the variety of applied ex vivo and in vivo models, accompanied by the physiological factors (variations in epidermal thickness and hair follicle density among species and anatomical site) limit broader consensus in the field [21].

Although nanøtechnology nanosystems may provide means to modulate the packing and phases of the lipid component of the stratum corneum by fluidization, the potential toxicity issues should not be neglected particularly for non-lipid based nanodermatologicals [9].

\section{SKIN PENETRATION OF NANOSYSTEMS}

In spite of the fact that the size limit for nanosystem able to penetrate stratum corneum remains to be debatable, it is accepted by the Scientific Committee on Consumer Products that only very small particles, size range below $10 \mathrm{~nm}$, are detectable in stratum spinosum in the epidermal layer [8]. DeLousie [21] proposed that the skin is a formable barrier to particle penetration; that the hair follicles serve as the collection sites for topically applied nanosystems and that their surface charge plays an important role in their penetration pattern, as the differences in the penetration have been observed for neutral and negatively charged particles. It seems that the nanocarriers penetrate preferably into the hair follicle canals rather than through stratum corneum. If this is the case, the skin penetration of nanocarrier-associated drugs will be the result of the carriers' accumulation within the hair infundibulum, the release of the drug within the hair follicle canal 
and finally diffusion of the substance. Nanosystems are expected to increase both the penetration depth and permeation rate of the substance [22]. Unsaturated fatty acids and phospholipids containing higher portion of unsaturated fatty acids (e.g. soy lecithin) play a role in the fluidization of the stratum corneum [9].

Several parameters including lamellarity, lipid composition, surface charge of the nanosystem, presence of the edge activators and/or penetration enhancers and total lipid concentration determine drug deposition into the deeper skin layers [18, 23,24].

The required size of nanosystems for successful trans(dermal) drug delivery remains to be extensively discussed [10]. For example, deformable liposomes with an average size of $120 \mathrm{~nm}$, have been shown to enhance the penetration of hydrophilic fluorescent compound for more than 5-fold into the deeper skin layers, as compared with larger vesicles (>190 nm) of the same lipid composition [25]. Decreasing the particle size of solid lipid nanoparticles has been confirmed to increase the occlusive effect on the skin consequently affecting skin hydration and drug permeability [26]. Besides the size effect, the effect of the nanosystem's rigidity/elasticity is important, as this feature will influence interaction of nanosystem with the stratum corneum and skin in general. Considering the (trans)dermal drug delivery. The distinction between particles which are soft and rigid in their nature is the feature that will affect nanosystems interaction with the stratum corneum and skin in general [22]. Typical examples of soft nanoparticles are elastic liposomes, whereas solid lipid nanoparticles (SLNs) represent rigid nanoparticles [26]. ]. It has been shown that the type and concentration of edge activator had great effect on the drug penetration via deformable liposomes through decreasing the particle size and increasing bilayer elasticity[24,27]. Furthermore, the surface charge of nanosystem has been also demonstrated to play a role in skin drug delivery [28]. 


\section{NANOSYSTEMS (NANOPHARMACEUTICALS)}

Nanosystems, often referred to as nanoparticles, nanovesicles, or nanopharmaceuticals, are in general expected to increase the bioavailabilty, biocompatibility and safety profiles of associated drug molecules, serving as carrier systems with specific properties related to their nanosize. Their ability to prolong and, at least to certain extent, control the release of associated drugs would potentially decrease the doses and dosing frequency while assuring the desired therapeutic effect [29].

Among different drug delivery systems investigated for improving (trans)dermal therapy, lipidbased nanosystems are of particular interest. They are commonly composed of physiologically acceptable lipids, usually non-toxic and degraded to non-toxic residues [10]. A unique advantage of lipid nanocarriers lies in the compatibility of their ingredients with the physiologically occurring compounds, i.e. stratum corneum constituents. The overview of the nanosized lipidbased systems classified as vesicular, particular or emulsion-based nanosystems is provided in the following chapters. In the second part on the review, the selected skin diseases and the tested nanopharmaceuticals are discussed in more details.

\section{PHOSPHOLIPID-BASED VESICULAR DRUG DELIVERY}

\section{NANOSYSTEMS}

\section{LIPOSOMES}

General considerations 
Liposomes are fully physiologically acceptable nanovesicles consisting of one (unilamellar liposomes), several (oligolamellar liposomes) or many (multilamellar liposomes) concentrically arranged lipid bilayers surrounding inner aqueous compartment(s). In addition, they may have a multicompartmental structure (multivesicular liposomes) [30]. The compatibility between their constituents (phospholipids, cholesterol and water) and skin constituents makes them superior skin drug delivery nanosystems. They have been investigated for the skin drug delivery for over 30 years [31]. Due to the specific structural properties liposomes are able to encapsulate/incorporate drugs of different sizes and lipophilicity. Hydrophilic drugs will be encapsulated into the aqueous compartment(s), lipophilic inside the bilayer, while amphiphilic will partition themselves between these two regions. Liposomal characteristics are determined by their lipid composition, membrane rigidity/elasticity, particle size, surface charge, number of lamellae and inner/outer aqueous phases [32]. Phospholipids were proposed to act as a penetration enhancers enabling alteration of the intercellular lipid matrix within the skin; therefore encapsulation of hydrophilic drugs in liposomes can increase their penetration into/through the skin [33]. Furthermore, liposomes may provide targeted delivery to skin appendages and assure localized depot of the lipophilic drug in the skin [33]. In addition, liposomes are able to incorporate poorly soluble drugs and alter their pharmacokinetics and skin bioavailability. Even empty liposomes have been shown to increase the skin hydration level which is of high importance in the treatment of xerosis cutis and atopic dermatitis [34]. Regarding the membrane properties, i.e. presence of surfactant or co-solvent in the bilayers, liposomes are categorized as conventional liposomes (with more rigid bilayers) and elastic liposomes (with pronounced bilayers elasticity), later including i) deformable liposomes, ii) ethosomes and iii) permeation enhancer containing vesicles, i.e. propylene glycol liposomes and invasomes (Figure 1). Considering the liquid nature of liposomal suspension and need for their 
retention at the skin as administration site, liposomes are usually incorporated in the suitable bases such as gels, creams.

\section{Conventional liposomes}

Conventional liposomes are the first generation of liposomes comprising of the neutral phospholipids (phosphatidylcholine), or the combination of neutral and charged phospholipids, originating either from natural or synthetic sources with or without addition of cholesterol (Figure 1A). Mezei and Gulasekharam [35] were the first to propose liposomes for skin application. They have claimed that triamcinolone acetonide incorporated in liposomes composed of dipalmitoylphoshatidylcholine and cholesterol increased drug deposition in rabbit's epidermis and dermis, while concentrations of the drug in thalamic region (potential place for side-effects) and urinary excretions were significantly reduced in comparison to control formulation. Similar fate of liposomally encapsulated drug has been shown for hydrocortisone [36,37] and local anesthetics tetracaine [38] and lidocaine [39]. Liposomal delivery increases the efficacy of treatments even at the significantly lower concentrations of active substances as compared to the conventional formulations. For example, replacing the moisturizing cream with liposomes reduced the therapeutic concentration of 5-aminolevulinic acid in photodynamic therapy by a factor of 40 while maintaining the same effect [40]. Additional advantage of using liposomes in dermatological treatments is the reduced skin irritation caused by substances like retinoids [41]. Conventional liposomes increased the skin delivery of vitamin D3 and dithranol in the treatment of psoriasis [42]. In the case of the plaque type psoriasis, the entrapment of dithranol in liposomes has promoted its epidermal bioavailability and enabled the dose lowering, resulting in 
the reduction of consequent dose-dependent side-effects [43]. Conventional liposomes have also been examined for the targeting to the skin appendages $[44,45]$, for improved treatment of hair follicle disorders such as alopecia. The liposomes comprising of dimyristoyl phosphatidylcholine, cholesterol and dicetylphosphate (8:2:1, mole ratio) significantly increased the deposition of finasteride in the hair follicles compared to hydroalcoholic drug solution [46]. Similar findings have been reported for liposomal minoxidil [47].

However, most of the studies confirmed that the conventional liposomes have negligible or no penetration potential across the stratum corneum and can therefore only slightly improve the delivery of drug to the deeper layers of skin and transdermally [32,33,48,49].

\section{Deformable (elastic) liposomes}

In the early 90th of the last century Cevc and Blume [23] introduced a new type of liposomes with increased bilayer elasticity, namely deformable liposomes (highly fluid vesicles), which become known as elastic, flexible, ultradeformable liposomes or under the trade name Transferosomes $^{\circledR}[50,51]$. Deformable liposomes are commonly composed of lipids and an edge activator that destabilizes the liposome bilayers thus increasing the membrane deformability/elasticity (Figure 1B). As a consequence, the vesicles should be able to squeeze through the pores in the stratum corneum smaller than $1 / 10$ of the vesicle diameter and transport entrapped drug deeper into the skin when applied under the non-occlusive conditions. In such a setting the osmotic gradient operating from the dry skin surface (15\% water) towards wet viable tissues (75\% water) drives vesicles through stratum corneum [52]. Honeywell-Nguyen and colleagues [53] confirmed that the intact elastic vesicles penetrate into the stratum corneum under the non-occlusive dressing; however, only few intact vesicles were found in the deeper horny 
layers. Cevc and Blume [54] confirmed the penetration of diclofenac through the skin using Transferosomes ${ }^{\circledR}$ as a carrier system; the therapeutically relevant concentrations of the drug were obtained in the target tissue. When hydrocortisone, dexamethasone or triamcinolone-acetonide in the deformable liposomes have been administered epicutaneously the drug levels were found to be comparable to those obtained by a subcutaneous injection of the same drugs. Interestingly, Transfersome ${ }^{\circledR}$-based corticosteroids were biologically active at doses several times lower than those currently used in the dermatologic formulations for the treatment of skin diseases [55]. Deformable liposomes have also been investigated as carriers for large molecular weight drugs, such as insulin. Applied under the non-occlusive dressing, Transferosomes ${ }^{\circledR}$ have been shown to deliver insulin through the non-compromised skin barrier with reproducible pharmacokinetics and the pharmacodynamic effects comparable to the subcutaneous injection [56]. The efficacy of deformable vesicles in skin delivery of drugs has also been evaluated by other research groups. Jain and colleagues [57] tested deformable liposomes for transdermal delivery of levonorgestrel. The peak plasma concentration of the drug was achieved after 4 hours and was maintained for 48 hours after a single topical application of deformable liposomes. Using deformable liposomes, the same group has also reported on the increased transdermal flux of poorly soluble zidovudine. The AUC (24 h) for elastic liposomes was found to be almost 12-fold higher than the control formulation; higher accumulation of antiviral drug has been found in target organs of reticuloendothelial system [58].

Although the main target of deformable liposomes has been the increased transdermal delivery of numerous drugs [59], they have been also studied as means for improved dermal therapy, such as the treatment of deep dermal infections. The elastic liposomes containing neomycin sulphate assured the enhanced skin deposition while histological studies showed complete eradication of 
Staphylococcal infections within 7 days [60]. Pandit and colleagues [61] demonstrated better penetration of miconazole nitrate across the skin and better antifungal activity in vivo in comparison to the conventional liposomes.

Cadena and co-workers [62] proposed deformable liposomes with flavonoides for the weight loss treatment. Quercitin and resveratrol were encapsulated into phosphatidylcholine liposomes containing sodium deoxycholate as edge activator. This innovative phospholipid nanosystem was suggested as a novel approach for dissolving the subcutaneous fat when applied as a subcutaneous injection. However, no in vivo data on the efficacy of the system are available up to now.

Trotta and co-workers [63] investigated topical administration of methotrexate, potent antipsoriatic drug known to cause numerous side-effects and hepatotoxicity when applied orally. Moreover, the drug is hydrophilic and mostly in a dissociated form, therefore its topical application is limited. The encapsulation of methotrexate in deformable liposomes resulted in the enhanced penetration of drug into the skin. In another study, methotrexate was entrapped in deformable vesicles containing oleic acid as an edge activator. Enhanced skin penetration of the drug through the stratum corneum with increased accumulation in the epidermis and dermis layers has been ascribed to the elasticity of vesicles and the penetration enhancing effect of oleic acid [64].

Despite the generally accepted mechanism of intact vesicle penetration, there is still substantial discussion whether deformable liposomes penetrate intact through the skin or act as the penetration enhancer. El Maghraby and co-workers [65] compared the deformable and conventional liposomes as the carriers for skin delivery of 5-fluorouracil. Better in vitro skin delivery of the drug was obtained via deformable vesicles as compared to the conventional liposomes. However, due to limited drug partitioning inside the skin the authors suggested that 
deformable liposomes are not penetrating intact into the skin rather then that the vesicle components act as the penetration enhancers promoting the skin deposition of the drug; contrary to claims proposed originally by Cevc and collaborators [23,52]. The similar speculations regarding the mechanism involved in the improved skin delivery of drug by elastic vesicles, i.e. penetration enhancing effect, has been suggested by Gillet's group. Bethametasone entrapped in the aqueous compartment of the vesicles via cyclodextrin complexation was released and diffused as free molecules through the stratum corneum thus partitioning itself into the viable skin tissue [24]. These results are in accordance with those reported by Bahia and co-workers [66]. Using calcein as hydrohophilic marker entrapped in the deformable liposomes they proved the penetration-enhancing effects of sodium cholate and ethanol. Ex vivo skin permeation and in vivo transdermal studies on hairless mice showed the reduced transdermal flux of calcein in comparison to the solution forms, suggesting that the transdermal absorption of calcein from the deformable vesicles is controlled by the release of the drug from the formulation deposited onto the skin surface. Moreover, fluorescence measurements of the receptor fluid after the addition of $\mathrm{Co}^{2+}$ quencher have revealed that permeated calcein existed essentially in the free form, thus contradicting the proposed penetration of intact vesicles [66].

\section{Ethosomes}

Ethosomes are soft phospholipid vesicles originally developed by Touitou and her group [67] as a novel skin delivery system. They are composed of phospholipids and water as the conventional liposomes, but in addition include high ethanol content (20-45\%, v/v) (Figure 1). Due to a wellknown skin permeation enhancing effect of ethanol, ethosomes are also categorized as the skin permeation-enhancing vesicles. The presence of ethanol enables the entrapment/incorporation of 
drugs with limited water solubility with rather high efficiency. Compared to the conventional liposomes of the same phospholipid composition, ethosomes are of significantly smaller size that can be attributed to high ethanol content. Ethanol may affect dissociation degree of a partially charged molecule at bilayer surface that can subsequently reflect to increased negative net surface charge of vesicles affecting decreased particle size of ethosomes [68]. The encapsulation efficiency of lipophilic drugs in ethosomes is higher in comparison to the conventional and especially the deformable liposomes. This is a consequence of the solubilizing effect of ethanol and the multilamellar morphology of ethosomes confirmed by Touitou and co-workers [69]. Moreover, ethosomes exhibited improved intracellular delivery into fibroblasts [70]. A proposed mechanism of improved skin drug delivery by ethosomes involves the dual fluidizing effects of ethanol on both the ethosomal lipid bilayers and the intercellular lipid matrix of stratum corneum. Compared to the deformable liposomes, which are able to increase the skin delivery only when applied under the non-occlusive dressing [51], ethosomes are efficient both under the nonocclusive [71,72] and occlusive conditions [71,73]. In vitro, animal and clinical studies have reported superiority of ethosomes in the skin delivery of minoxidil [67], trihexyfenidil $\mathrm{HCl}$ [71], cannabinoids [74], bacitracin [75], erithromycin [76,77] and testosterone [73].

Ainbinder and Touitou (73) compared the efficiency of ethosomes in transdermal delivery of testosterone across the rat skin in vivo to a registered gel formulation of the drug. The AUC of the drug from ethosomal formulation was found to be $64 \%$ greater than with the gel formulation. However, their study lacks reliable evidence supporting the claim of carrier mediated, rather than facilitated transport. In a recent study with surfactant-modified testosterone propionate ethosomes, the higher transdermal flux and lower lag time were obtained in comparison to the conventional liposomes and ethanolic solution of the drug [78]. Ex vivo studies on dermatomed 
human cadaver skins revealed the enhanced transdermal permeation of the ethosomal melatonin as compared to the conventional liposomes and alcoholic solution of the drug [79].

Potential of ethosomes in the transdermal delivery of anti-inflammatory drugs (or isolated plant medicals) has been reported by several research groups. The assessment of transdermal delivery of diclofenac sodium from different phospholipid vesicles demonstrated similar transdermal flux of both ethosomes and deformable liposomes in comparison to the conventional liposomes [80]. Using the isolated human epidermis, Chourasia and co-workers [81] investigated potentials of ethosomes for transdermal delivery of ketoprofen. Paolino and colleagues [82] studied the penetration of ethosomal ammonium glycyrrhizinate through the isolated stratum corneum and viable epidermis as well as anti-inflammatory effect on human volunteers. Ethosomes have also been proposed for transdermal delivery of phytochemicals, such as capsaicin [83].

Ethosomes have been able to increase the effectiveness of topical anesthesia. Transdermal flux of lidocaine ethosomes was significantly greater than those obtained with the conventional liposomes and ethanolic solution of the drug [84].

They were also studied for improved skin therapy in dermatology providing increased drug solubility and enhanced penetration through the stratum corneum. Clinical investigation of ethosomal acyclovir in the treatment of recurrent herpes labialis demonstrated advantages of using ethosomes over the commercial product; time necessary for crusting of the lesions and loss of crusts were significantly reduced by applying ethosomal formulation [85].

Verma and Fahr [86] reported on potential of phospholipid vesicles embodying $10-20 \%(\mathrm{v} / \mathrm{v})$ of ethanol in delivering the skin-impermeable drugs such as cyclosporine A for the treatment of skin inflammatory diseases, i.e. psoriasis and atopic dermatitis. Dubey and colleagues [87] tested ethosomes with methotrexate for the topical treatment of psoriasis. Ex vivo skin permeation 
studies on dermatomed human cadaver skin showed better flux of the drug and skin deposition by ethosomes than with other vesicles. However, studies based only on in vitro and ex vivo penetration assessments do not always correlate to in vivo conditions as reported by Cevc and colleagues [88].

For the treatment of alopecia, Meidan and Touitou [89] studied ethosomes with minoxidil in vitro. The quantity of the drug accumulated into the skin of nude mice after the application of ethosomes was 2.0, 7.0 and 5.0 fold higher as compared to the ethanolic phospholipid dispersion, hydroethanolic solution and ethanolic solution of the drug.

Ethosomes have also been suggested for topical therapy of different skin allergies including urticaria, pollinosis and atopic dermatitis. Ex vivo skin permeation studies in the mice model showed high penetration potential of cetirizine compared to the conventional liposomes, while in vivo pharmacodynamic study proved the reduction in starching and erythema scores, skin hyperplasia and dermal eosinophil count [90]. The application of ethosomal tacrolimus in the treatment of atopic dermatitis enabled greater ex vivo penetration of the drug than with conventional liposomes in the mice skin model. Furthermore, pharmacodynamic study displayed the lowest ear swelling compared to the conventional liposomes and commercial ointment, and effectively impeded accumulation of mast cells in the ear of the mice, suggesting efficient suppression for the allergic reactions [91].

Encapsulation of psoralen into ethosomes resulted in the increased penetration through the stratum corneum and skin deposition. In vivo skin microdialysis study showed that the peak concentration and area under the curve of psoralen from ethosomes were approximately 3 and 2 times higher than those of psoralen from the tincture formulation indicating potential of ethosomal psoralen for improved treatment of vitiligo [92]. 


\section{Penetration enhancer-embodying liposomes (PEVs)}

This term refers to elastic liposomes composed of the phospholipids and penetration enhancer as bilayer building compounds (Figure 1D). Propylene glycol or diethylene glycol monoethyl ether $\left(\right.$ Transcutol ${ }^{\circledR}$ ) have been commonly used as the penetration enhancers [93,94]; however, some authors used the cineole and capryl-caproyl macrogol 8-glyceride (Labrasol ${ }^{\circledR}$ ) [95]. The elastic vesicles containing terpens as the penetration enhancer also known as invasomes [96] are presented separately at the end of this chapter.

Propylene glycol-containing liposomes (PG liposomes) have been proposed by Elsayed and colleagues [93] as a new type of phospholipid vesicles for improved skin drug delivery; however it is worth noting that these vesicles were investigated earlier for topical drug delivery via mucosal route under different name, i.e. the polyol dilution liposomes [16,97,98,]. Those liposomes were composed of phospholipids, propylene glycol (PG) and water and characterized by the increased entrapment efficiency for poorly soluble drugs due to the solubilizing effect of PG $[17,99]$. PG liposomes can be prepared using PG as a solvent for the phospholipids and lipid drug [93,97-99-87] or as a part of the aqueous phase of formulation [94,100]. The presence of PG or other penetration enhances in the phospholipid bilayer significantly increases the elasticity of vesicles [100,101]. Preliminary in vivo skin deposition study using an animal model has shown superiority of PG liposomes over the conventional, deformable liposomes and ethosomes in the skin delivery of local anesthetic cinchocaine [93]. Moreover, the PG liposomes were superior to deformable liposomes in delivery of diclofenac sodium in the permeation studies performed on the artificial stratum corneum-mimicking membranes [100].

Manconi et al. [101] evaluated diclofenac (both as acid and salt form) loaded liposomes containing Transcutol ${ }^{\circledR}$. Increasing the concentration of penetration enhancer resulted in the 
better drug encapsulation, while rheological experiments revealed that Transcutol ${ }^{\circledR}$ was able to improve the bilayer fluidity. Compared to commercial gel, Transcutol ${ }^{\circledR}$-containing vesicles enabled enhanced penetration of the both drug forms into and through the skin. In another study PG liposomes were investigated for transdermal delivery of curcumin as anti-inflammatory agent. Comparison pf PG liposomes with other elastic vesicles, i.e. ethosomes and deformable liposomes revealed the highest entrapment of curcumin in the PG liposomes (> 90\%). The same formulation also exhibited the highest transdermal flux across the rat skin. The superiority of PG liposomes was confirmed in in vivo anti-inflammatory study measuring the inhibition of the paw edema [102]. Evaluation of different penetration enhancers used for the preparation of PEVs with quercitin confirmed that PG and polyethylene glycol 400 enable similarly high drug accumulation into and through the skin [103]. The same group also reported on the potentials of PEVs for cutaneous delivery of minoxidil. Among different penetration enhancers examined, Labrasol ${ }^{\circledR}$ - and cineole- containing PEVs were found to be able to deliver a higher amount of the drug than controls [104].

The recent study by Wang and colleagues [105] reports on the use of novel penetration modifiers embodied into the bilayers of phosphatidylcholine liposomes, namely 1,2-hexanediol and 1,4cyclohexanediol, able to enhance the targeted delivery of ketoconazole into the skin.

\section{Invasomes}

Invasomes are a novel type of elastic phospholipid vesicles composed of phosphatidylcholine, ethanol and a mixture of terpenes as penetration enhancers. Invasomes containing $3.3 \%$ ethanol and $1 \%$ of the terpene mixture (cineole:citral:d-limonene=45:45:10) have shown to significantly 
enhance the skin penetration and deposition of the highly hydrophobic photosensitizer temoporfin (mTHPC) in comparison to the vesicles without terpenes and conventional liposomes [96]. Invasomes could provide the efficient delivery of mTHPC in photodynamic therapy [106]. The precise mechanism of the penetration enhancing ability of invasomes is debatable and should be further investigated. It is hypothesized that synergistic effect of phospholipids, terpens, ethanol might play a role in increased delivery of active substances into the skin [106].

\section{Penetration enhancer-embodying deformable liposomes}

Hiruta and colleagues [107] formulated bleomycin-loaded ultra-deformable liposomes composed of egg phosphatidylcholine and sodium cholate and additionally containing beta-sitosterol 3-betaD-glucoside (Sit-G) as a penetration enhancer. The presence of Sit-G increased drug entrapment, in vitro stability, and significantly increased the distribution of bleomycin in the epidermis and dermis as compared to the ultra-deformable liposomes without Sit-G.

The overview of main characteristics, advantages and limitations of described systems in provided in Table 1.

\section{OTHER PHOSPHOLIPID VESICLES FOR IMPROVED SKIN THERAPY}

pH-sensitive liposomes 
$\mathrm{pH}$-sensitive liposomes become destabilized in acidic $\mathrm{pH}$ such as in endosome inside the cells, enabling the release of the entrapped material into the cytoplasm. Although mostly studies to deliver the genetic material via parenteral route, two decades ago Yarosh and co-workers applied these type pf liposomes in dermatology. Yarosh and co-workers designed and evaluated pHsensitive T4N5 liposomes containing a DNA repairing enzyme (T4 endonuclease 5), specific for solar UV-induced skin DNA damage [108-109-100]. T4N5 liposomes applied after the UV exposure, penetrated human skin and delivered DNA repairing enzyme into keratinocytes and epidermal Langerhans cells in 15 volunteers with preceding skin cancers [111]. Moreover, daily applications of T4N5 liposome-based lotion for a period of one year to the 30 xeroderma pigmentosa patients with sun-damaged skin and with the history of skin cancer or actinic keratosis, lowered the rate of new actinic keratosis and basal cell carcinomas significantly [109]. To the best of our knowledge, this formulation reached the Phase III of clinical investigation [112].

\section{Biphasic vesicles}

The rationale behind these vesicles was to build the vesicles from excipients that provide synergistic skin permeation enhancement. Biphasic vesicles are structurally related to liposomes and represent the multicompartmental delivery systems. Those vesicles exhibit mixed lipid membrane characteristics, multicompartmental structure and positive charge. Biphasic vesicles appear to interact with the intercellular lipids of stratum corneoum and enhance the lipoidal pathway of penetration affecting the molecular rearrangement of intercellular lipids [113]. King and co-workers developed biphasic vesicles-based novel delivery system Biphasix ${ }^{\mathrm{TM}}$ as a superior delivery system for transdermal delivery of insulin. Basal levels of insulin were 
observed in the serum of diabetic rats treated with Biphasix-insulin up to 3 days after patch application [114]. In consequent experiments, the authors proved that lymphatic transport of insulin after non-invasive topical administration is taking place [115]. Topical application of biphasic vesicles carrying interferon alpha in a guinea pig model resulted in sustained delivery of interferon locally into skin, exhibiting their potential in treatment of anogenital warts. Biphasix ${ }^{\mathrm{TM}}$ interferon-alpha-2b cream used in the animal study had a physical appearance of a soft cream [116]. Biphasic vesicles entrapping interferon alpha delivered clinically relevant levels of interferon across intact human skin and elicited marked therapeutic effect in patients [117].

\section{PARTICULATE LIPID-BASED NANOSYSTEMS}

\section{Solid lipid nanoparticles (SLNS)}

Solid lipid nanoparticles (SLNs) are comprised of lipids $(0.1-30 \%$, w/w) that are solid at room and body temperatures and surfactants (0.5-50\%) serving as stabilizing agents (Figure 2A). They have been introduced in 1991 as an alternative to vesicular nanosystems, emulsions and polymeric nanoparticles. SLNs contain adhesive and occlusive excipients that form a thin film on the skin surface, thus reducing water evaporation and retaining skin moisture $[26,118,119$,$] . The$ occlusive property enhances drugs penetration into the skin and can be increased by decreasing the particle size (at given lipid concentration) or by increasing the lipid nanoparticles concentration (at given particle size) [120]. SLNs are biodegradable and biocompatible, having low toxicity and feasibility for scale up and sterilization. Physicochemical features and drug characteristics influence the drug loading and distribution within particles and dispersions. Generally, lipophilic drugs are better encapsulated than amphiphilic and hydrophilic drugs $[121,122]$. The lipid composition and drug lipid solubility determine drug distribution within the 
particles that consequently reflect to release kinetics [123-125]. The interactions between SLNs and keratinocytes suggest that SLNs in nanosize range may provide advanced skin therapy [126]. SLNs were investigated to improve the treatment of skin diseases such as atopic dermatitis, psoriasis, acne, skin mycosis and inflammations [119]. To facilitate dermal application by achieving the appropriate viscosity of formulation, the fluid dispersions with low lipid content $(<10 \%)$ can be incorporated into a gel or cream base compatible with nanoparticles, similarly like other vesicular nanosystems [127].

Well documented evidence supports the role of SLNs in improved delivery of antifungals. Recent study by Vaghasiya and co-workers [128] confirmed the ability of SLNs to improve retention of terbinafine hydrochloride inside the skin and to reduce fungal burden in rats in a shorter time than marketed formulation. In vivo evaluation of econazole nitrate containing SLNs confirmed a rapid penetration of the drug through stratum corneum and its increased diffusion in the deeper skin layers [129].

By the right choice of lipid composition SLNs have been able to overcome limitations of conventional corticosteroid therapy in dermatology [130]. SLNs reduced percutaneous absorption of betamethasone-17-valerate in both the impaired and intact skin. When the barrier was intact, the reservoir effect was more evident and the drug partitioning into the different skin layers was dependent on the lipid properties of the SLNs [125].

Investigations of reseveratrol as a naturally occurring anticarcinogenic compound for the treatment of skin cancers have been received particular attention. Teskač and Kristl [126] confirmed cellular uptake of resveratrol when loaded into SLNs and improved effects of the drug on the cellular fate. SLNs with a size below $180 \mathrm{~nm}$ passed rapidly through keratinocyte membranes causing no significant changes in cell morphology, metabolic activity or cell cycle. 
SLNs were concentrated around nuclei, releasing resveratrol in a sustained manner to express its cytostatic effect with prominent S-arrest of cell cycle and a large drop of G2/M phase. The same group [126] investigated antioxidative potentials of liposomal resveratrol and found that liposome-mediated uptake of resveratrol was more effective for the improvement of the cellstress response. Resveratrol loaded into negatively charged oligolamellar liposomes (84 nmsized) protected cells from free radical damage [131].

Although SLNs have numerous advantages as discussed above, there are some limitations, too. One of them is poor loading capacity which is limited to about $10 \%$ of the amount of lipid (leading to about $1 \%$ of the final dispersion) to ensure stability of the system. Namely, highly ordered crystalline lipid matrix leave little place for drug incorporation that can expelled out during the storage [127]. To overcome these deficiencies, second generation of lipid nanoparticles, i.e. nanostructured lipid carriers (NLCs) were introduced in the late 90th of the last century [120]. NLCs are able to incorporated lipophilic drugs to a greater extent than SLNs; however the entrapment of hydrophilic drugs is limited.

\section{Nanostructured lipid carriers (NLCs)}

NLCs (Figure 2B) are produced using the blends of solid and liquid lipids (mixed in ratios ranging from 70:30 to up to 99.9:0.1) that are stabilized by surfactants as the SLNs. The presence of liquid lipids with different fatty acid chains prevents the formation of arranged lipid matrix, leading to formation of less ordered lipid matrix. Such imperfect matrix permits better accumulation of larger amounts of drug. Drug solubility is often higher in an oily phase contributing to increased loading efficiency [132]. The fluid lipid phase of NLCs can be 
embedded into the solid lipid matrix or be localized at the surface of solid platelets and the surfactant layer [127]. NLCs include all advantages of SLNs reported earlier such as biodegradability, occlusion effect, modified drug release, delivery of drug to a specific sites of skin, increased drug stability, etc., and in addition enable improved drug loading and increased shelf life [127].

Specific structure of NLCs can allow biphasic pattern of drug release with initial burst effect followed by a sustained release due to different melting points of solid and liquid lipids [133]. By changing the ratio of solid and liquid lipids in NLCs, the drug release, permeation and pharmacodinamyc activities can be modulated [134]. Physicochemical properties of NLCs such as the lipid composition, size and surface charge influence the delivery of encapsulated drug into the skin [127].

Many attempts were employed to explore the potentials of NLCs in dermatology $[119,120]$. For example, Gomes and colleagues [135] investigated potentials of finasteride and minoxidil loaded NLCs for the treatment of alopecia in vitro. A high loading efficiency was achieved for finasteride (70-90\%), while less than $30 \%$ was achieved for minoxidil nanoparticles. Both drug formulations were physically stable, provided prolonged release of the drugs and sufficient enabled penetration of drugs into the skin layers.

The potential of NLCs in the therapy of psoriasis has been suggested by Agrawal and collaborators [136]. They have assessed acitretin NLCs-based gel in ex vivo and in clinical studies. The formulation showed increased penetration of acitrecin into the human cadaver skin compared with a reference gel. The double-blind clinical study on psoriatic patients reported improvement in a therapeutic response and reduction in the local side effects. However, the low number of patients $(\mathrm{n}=6)$ is considered as a limitation. 
NLCs containing both calcipotriol and methotrexate in one formulation have been suggested to strengthen the topical therapy of psoriasis [137]. Ex vivo studies performed on hyperproliferative mice skin demonstrated increased skin permeation of metrotrexate, while the penetration of calcipotriol was reduced. Good correlation of obtained results has been confirmed in vivo by confocal laser scanning microscopy [137].

Modified NLCs for topical delivery of tacrolimus (T-MNLC) in the therapy of atopic dermatitis and other skin inflammation disorders have been shown to enable high entrapment efficiency of the poorly soluble drug, enhanced stability and improved skin deposition [138]. In vivo evaluation of T-MNLC based on restoration of skin barrier, therapeutic effectiveness and safety aspects imply the potential of developed formulation in the therapy of atopic dermatitis [139].

Several studies report on the potentials of NLCs in (trans)dermal delivery of NSAIDs for the local treatment of rheumatic diseases (by non-selective COX inhibitors) as well as skin inflammation diseases, e.g. tumors, injuries and wounds (by selective COX-2 inhibitors). For example, penetration of flurbiprofene through the rat skin was found to be 4-5-folds increased after $12 \mathrm{~h}$ by using NLCs compared to the solution of free drug [140]. Ricci et al. [141] reported on higher indomethacin transdermal flux and prolonged anti-inflammatory activity by NLCbased gel in comparison to the control gel. In another study Joshi and Patarvale [134] compared NLCs-based celecoxib gel with control micellar gel. Ex vivo penetration of the drug from the NLC-gel was less than from the micellar-gel. The in vivo evaluation of the percentage edema inhibition produced by NLCs and micellar gel demonstrated a significantly higher inhibition by NLC-based gel up to 24 hours [134]. 


\section{MISCELLANEOUS}

\section{Micro- and nano-emulsions}

Literature reports on potential of micro- and nano-emulsions in dermatology often do not discriminate between microemulsions and nanoemulsions in respect to the size of the droplets. Physicochemically, microemulsions are thermodynamically stable colloidal dispersions of water and oil stabilized by a surfactant and, often, a cosurfactant [31]. The active compound (drug) is solubilized inside microemulsion, wherein the formulation ingredients facilitate the penetration into the skin. The selection of cosurfactant is usually based on its penetration enhancing potential. The occlusivity also acts on improving the drug penetration [142]. Nanoemulsions are metastable colloidal systems. The method of preparation is directly affecting their properties and can be manipulated to design and optimize the delivery systems [143]. Compared to the conventional emulsions, microemulsions are characterized by low interfacial tension due to the high ratio of surfactant and co-surfactant responsible for good physical stability of formulation. On the other hand, high ratio of surfactant may affect the system's compatibility of formulation with the skin [144] . Recently, multiple W/O/W nanoemulsions as superior delivery system for acyclovir have been proposed [145].

\section{Cohleates}

Cochleates are tubular shaped structures derived from liposomes. They are actually the precipitates obtained through the interaction between phosphatidylserine and calcium, able to 
entrap wide variety of drugs [146]. Although designed mostly to target oral and parenteral routes of drug administration, cochleates, may have potentially serve as a topical drug depot system [147].

\section{(PHOSPHO)LIPID-BASED NANOPHARMACEUTICALS WITH POTENTIAL IN} (SELECTED) SKIN DISEASES

\section{Antimicrobial skin therapy}

Skin represents a unique environment in respect to microbiome. An extensive review on the skin microbiome, including bacteria, fungi, viruses, archaea and small arthropods colonizing the skin surface, has been recently published by Kong and Segre [148]. Antimicrobial agents and antibiotics have been traditionally used topically to treat various skin diseases such as acne (e.g. Propionibacterium acnes) [149], persistent bacterial skin infections [150,151], methicillinresistant Staphylococcus aureus (MRSA) infections or infections of prosthetic devices implanted into the skin (Staphylococcus epidermidis) [152]. Particularly interesting are fungal skin and nail infections which remain a major reason for patient visits to dermatologists. Antifungal therapy is mostly based on poorly soluble azole agents, which suffer from limited bioavailability due to solubility issues [153]. Additional limitation for effective antimicrobial therapy is the increasing resistance against most potent antimicrobials.- It is expected that encapsulation of drug in specific nanosystem will enable its improved delivery to the target sites enabling dose reduction while increasing the specificity[152,154].

The limited success of skin antimicrobial therapy may be attributed to the challenge most of the antimicrobials face when acting against biofilms [151]. Bacterial biofilms are a common cause of 
recurring infections that are unresponsive to drug therapy and are recognized as a serious challenge in antimicrobial therapy.

Pevaryl ${ }^{\circledR}$ Lipogel was the first approved antifungal liposome product promoting the advantages of liposomes in topical skin therapy [155]. Encapsulation of vancomycin within cationic liposomes has been shown to lead to enhanced inhibition of Stapyhylococcus epidermidis. Cationic liposomal surface enabled adsorption of vesicles onto biofilms and skin-associated bacteria. The adsorbed liposomes were also able release drug over 18 hour regrowth period, assuring prolonged antibacterial action [156].

Benzyl penicillin (penicillin G) was successfully encapsulated in cationic liposomes and its activity against Staphylococcus aureus biofilms confirmed [157]. Metronidazole, one of the drugs with very limited solubility, was successfully encapsulated into various types of liposomal systems [15,158]. A very promising approach was proposed by Vogt et al. [159] of using PVPiodine in hydrosomes, specific type of liposomes in hydrogels, for reduced rejection of skin grafts.

Ethosomes have been shown to improve delivery of various antimicrobials such as for example acyclovir [85] and erythromycin [76]. Godin and Touitou [75] demonstrated penetration of bacitracin into deep skin layers and co-penetration of both the drug and phospholipids into the fibroblasts. In vivo experiments have proven efficient healing of Staphylococcus aureus deep dermal infections when mice were treated with ethosomal erythromycin. On the contrary, no subdermal healing was observed in infected animals treated with hydroethanolic solution of the 
drug [77]. Enhanced ex vivo and in vivo skin deposition of antifungal drug voriconazole has been confirmed as well [160].

For the topical treatment of fungal infections, Elmoslemany et al. [161] prepared and evaluated miconazole nitrate-loaded PG liposomes. Compared to the conventional liposomes, PG liposomes exhibited stronger antifungal activity and enhanced skin deposition.

SLNs and NLCs were proposed as controlled release delivery systems for topical clotrimazole therapy [162].

\section{ANTIACNE TREATMENT}

Acne is a chronic inflammatory dermatosis of the pilosebaceous unit with up to $80 \%$ prevalence among adolescents. The readers are referred to the reviews on novel treatment approaches based on the use of delivery systems by Castro and Ferreira [163] and Date et al. [164]. Delivery of antiacne agents in vesicular and particulate nanosystems represents an innovative alternative to minimize the side effects, while maintaining the efficacy of the treatment, based on the controlled release properties and improved drug penetration into the skin or into the pilosebaceous unit [163]. Although no anti-acne therapy based on nanopharmaceuticals has reached the market yet, several promising approaches are listed below.

The superiority of liposome-encapsulated clindamycin hydrochloride in the treatment of acne has been first proposed by Škalko and co-workers. In clinical trials, the liposome formulation significantly decreased the numbers of pustules as compared to the control formulation [165]. Similar findings have been later demonstrated by Honzak and Šentjurc [166]. Liposomal delivery systems based on antimicrobials for anti-acne treatment have been confirmed to be superior to 
non-liposomal systems [31]. Liposomal delivery system for lauric acid, a natural compound from coconut oil, was proposed as innate, safe and effective therapeutic medication for acne treatment. Lauric acid-loaded liposomes have been shown to fuse with the membranes of Propionebacterium and release lauric acid directly into the bacterial membranes [149]. Improved treatment of Propionebacterium acnes with marked reduction in adverse symptoms has also been demonstrated with liposomes containing benzoyl peroxide [167].

Advantages of using SLNs for the acne treatments have been exhibited by improved photostability of retinoids, enabling lesser drug irritancy and greater skin tolerance [168]. SLNs were shown to enhance skin penetration of cyproterone acetate for 4-folds, compared with nanoemulsion and cream. Incorporation of the drug into the lipid matrix of nanostructured lipid carriers and microspheres resulted in a 2-3-fold increase in cyproterone acetate absorption [169].

Encapsulation of isotretinoin-hydroxypropyl- $\beta$-cyclodextrin (HP- $\beta$-CD) complex into the deformable liposomes has improved the skin delivery of isotretinoin for the treatment of acne. Transdermal flux was found to be 15-21-folds higher than that obtained from the drug in solution, and 4-5-folds higher than that obtained with the drug-cyclodextrin complex in a solution form. Moreover, the skin irritation study confirmed the significant reduction in irritation potential of isotretinoin elastic liposomal formulation in comparison to the free drug [170].

\section{DERMATO-ONCOLOGY}

Most of the advances of nanotechnology can be seen in the field of dermoscopy and confocal microscopy for the early detection of sub-clinical melanoma [2]. In respect to the treatment of 
melanoma, several lipid-based delivery systems seems to offer means for improved drug delivery.

Elastic liposomes have been studied for skin delivery of antitumor drugs. In vitro data revealed that the LD50 of bleomycin from Bleosome ${ }^{\mathrm{TM}}$ (elastic liposomes containing 10\% sodium cholate) was 3-fold higher than the free bleomycin solution in the cells of human squamous cell carcinoma (SCC) and nearly 30 times higher in the human cutaneous keratinocytes [171].

Paclitaxel-loaded ethosomes ${ }^{\circledR}$ have been proposed for the treatment of actinic keratosis and squamous cell carcinoma. Improved permeation of paclitaxel through the stratum corneum- and isolated epidermis- membrane models have been proven as well as the increased antiproliferative activity in a squamous cell carcinoma model [172]. Several studies (reported in previous chapters on liposomes and SLNs) emphasize the role of lipid based nanosystems in delivery of enzymes (T4 endonuclease 5) and anti-inflammatory drugs (e.g. celecoxib) in the prevention of skin cancer, i.e. treatment of precancerous actinic keratosis. The high potential of different nanosystems (elastic liposomes, $\mathrm{pH}$ sensitive liposomes, nanoemulsions, NLCs) in the treatment and prevention of skin carcinoma has been confirmed in in vivo animal and clinical studies (Table 2).

\section{GENE DELIVERY AND PLASMID-BASED VACCINES}

Gene therapy is defined as the insertion of a gene into recipient cells [173]. The skin is a very attractive organ for gene therapy, as it is easily accessible and the therapy outcome of skin treatment can be easily monitored. 
Lipid-based nanosystems have been tested as means of non-invasive delivery of genetic material into/through the skin to their introduction as possible carriers for non-invasive gene delivery. For extensive review on liposomes as non-viral gene delivery system, the readers should refer to Jeschke et al. [174]. Enhancement of dermal and epidermal regeneration represents a crucial target for the treatment of wounds, including burns. New strategies for the delivery of growth factors were proposed based on gene therapy [174].

Cholesterol containing cationic liposomes encapsulating an expression plasmid vector for cDNA were shown to be able to deliver biologically active proteins to the skin. It is known that keratinocyte growth factor (KGF) stimulates epithelial cell differentiation and proliferation, major steps in successful wound healing. Liposomal cDNA gene complex was proposed as delivery system for KGF therapy. Clear improvements in the epidermal and dermal regeneration were seen in rats with acute wounds [175].

Kim et al. [176] showed that deformable cationic liposomes, prepared using a cationic lipid, 1,2dioleoyl-3-trimethylammoniumpropane (DOTAP), and sodium cholate, were able to transfect several cell lines and after a single administration on the intact mice skin transport the genes into several organs for 6 days. In another study, ultradeformable liposomes containing edge activators sodium cholate or sodium deoxycholate could also deliver DNA into mice transdermally [177]. Biphasix, biphasic lipid vesicles, used as a carrier for plasmid DNA were shown to induce the gene expression in the lymph nodes. Interestingly, intradermal injection resulted in expression in the skin and gene gun-delivered genetic material was found expressed both in skin and lymph nodes [178].

\section{VACCINES}


Topical vaccines based on the advancements in nanotechnology are one of the most promising pipelines in nanodermatology. Topical vaccination provides an efficient way to activate effectorT-cells and induce immune responses. Currently, the main challenges for cutaneous immunization are to enhance the transport of antigens across the skin barrier and to improve the immunogenicity of topically applied subunit vaccines [179]. Hair follicles were also shown to be a penetration pathway and important target for topical vaccination [2].

Formulation of antigens in carriers of nanosize range for transcutaneous route is gaining more and more popularity [179-181].

Transferosomes ${ }^{\circledR}$ were used a carrier for different antigens, for example gap junction protein $[182,183]$ and tetanus toxoid $[184,185]$ and shown to induce immune response comparable to subcutaneous injection. Mishra and co-workers [186,187] showed the superiority of elastic liposomes with hepatitis B surface antigen. Recently, Chopra and Cevc [188] confirmed that epicutaneous immunization with tetanus toxoid in deformable liposomes protects mice against tetanus.

Baca-Estrada and co-workers [189] proposed biphasic delivery system as a suitable carrier for antigens able to induce antigen-specific immune responses.

More research is needed to determine the predominant route as well as the effect of the nanocarrier characteristics on the penetration and immunization potentials of various nanosystems.

The potentials of different (phospho)lipid-based nanopharmaceuticals in the treatment of various skin diseases and transdermal administration of drugs and biologically potent molecules are confirmed in numerous in vivo and clinical studies (Table 2). The success of extensive research 
resulted in several registered products, already available on the market. Table 3 summarizes the current state-of-art in the product development of nanosized lipid-based drug delivery systems.

\section{TOXICITY}

Nanosized systems carry intrinsic skin toxicity, in respect to their small size and limited ability of the skin to bio-process the exogenous material [190]. In respect to skin, especially the skin with damaged barrier properties such as in atopic dermatitis for example nanotoxicity needs to be addressed [7]. The effects of a long term deposition of nanoparticles in the skin remain to be explored [22]. The advancements in fluorescence microscopy such as the development of superior fluorescent dyes and probes provided a deeper insight on cellular uptake and the trafficking of nanoparticles within the cellular environment [191]. The advanced dyes and accompanying methods provide means to optimize delivery systems in respect to both intracellular localization of nanoparticles and toxicity concerns related to that particular delivery system, with focus on the effect of particle size on both issues [126].

Moreover, very little is known about the cumulative effects of exposure to various nanosized particles, especially cosmetic products. This concern was also addressed by EU through the project: Engineered Nanoparticles: Review of Health and Environmental Safety (ENRHES), funded by EU in 2008. Several initiatives were launched to address the exciting field of nanomedicine in dermatology, such as for example Nanodermatology Society (2010) focused on promoting a greater understanding of both scientific and medical aspects of nanotechnology in dermatology [21].

Phospholipid vesicle-based formulations for (trans)dermal drug delivery, such as Diractin ${ }^{\circledR}$, have been proven in many cases to be completely safe for continuous use [192]. However, each 
formulation needs to be carefully studied during the preclinical and clinical investigation before its recommendation for clinical use. Clinical investigations with soy lecithin/cholesterol liposomes containing econazole, hydrocortisone or local anesthetic indicated no adverse effects. Slight erythema was observed at the site of administration of liposomal tetracaine under the occlusive dressing in a few subjects, but it resolved spontaneously within 3 hours [38]. The clinical studies with liposomal econazole indicated less local irritation than econazole cream; the lipid vesicles minimized the irritation potential of the drug [155].

On the other hand, microemulsions, comprising of the relatively high surfactant concentration may cause toxic effects, especially if applied on the diseased skin with impaired function of the stratum corneum [31].

\section{CONCLUDING REMARKS}

It can be concluded that opportunities for improved skin therapy based on the advances in nanotechnology and development of nanosized delivery systems are expanding, both in the academia and industrial set up. (Trans)dermal route and recently revived hair follicles targeting [193-199]. Multidisciplinary approaches in nanodermatology are needed to understand the mechanisms of interactions between nanomaterials and the skin, particularly diseased skin. Remarkable number of (phospho)lipid-based nanopharmaceuticals for skin therapy are already on the market or in the late phases of clinical studies (Table 3). The patents in nanotechnology are being issued at a geometric rate indicating a strong focus of various industries, including pharmaceutical, cosmeceutical and biotechnological. However, many unanswered questions and technical challenges remain to be addressed, particularly the long term toxicity issues. 


\section{CONFLICT OF INTEREST}

The authors report no conflict of interest.

\section{References}

[1] Hay RJ, Johns NE, Williams HC, Bolliger IW, Dellavalle RP, Margolis DJ, Marks R, Naldi L, Weinstock MA, Wulf SK, Michaud C, Murray CJL, Naghavi M. The global burden of skin disease in 2010: An analysis of the prevalence and impact of skin conditions. J Invest Dermatol $2014 ; 134: 1527-34$.

[2] Fireman S, Tolendo O, Neimann K, Loboda N, Dayan N. A look at emerging delivery systems for topical drug products. Dermatol Ther 2011; 24:477-88.

[3] Couvreur P, Vauthier C. Nanotechnology: Intelligent design to treat complex disease. Pharm Res 2006; 23:1417-50.

[4] Riehemann K, Schneider SW, Luger TA, Godin B, Ferrari M, Fuchs, H. NanomedicineChallenge and perspectives. Angewandte Chemie 2009; 48:872-97.

[5] Gao H, Zhang Q, Y, Yu Z, He Q. Cell-penetrating peptide-based intelligent liposomal systems for enhanced drug delivery. Curr Pharm Biotech 2014; 15: 210-19. 
[6] Saraceno R, Chiriozzi A, Gabellini M, Chimenti S. Emerging applications of nanomedicine in dermatology. Skin Res Technol 2013; 19:e13-19.

[7] Bouwstra JA, Ponec M. The skin barrier in healthy and diseased state. Biochim Biophys Acta 2006; 1758:2080-95.

[8] Prow TW, Grice JE, Lin LL, Faye R, Butler M, Becker W, Wurm EMT, Yoong C, Robertson TA, Soyer HP, Roberts MS. Nanoparticles and microparticles for skin drug delivery. Adv Drug Deliv Rev 2011; 63:470-91.

[9] Banerjee R. Overcoming the stratum corneum barrier: a nano approach. Drug Deliv Transl Res 2013; 3:205-8.

[10] Baroli B. Penetration of nanoparticles and nanomaterials in the skin: Fiction or reality? J Pharm Sci 2010; 99:21-50.

[11] Geusens B, Strobbe T, Bracke S, Dynoodt P, Sanders N, Van Gele M, Lambert J. Lipidmediated gene delivery to the skin. Eur J Pharm Sci. 2011; 43:199-211.

[12] Schätzlein A, Cevc G. Nono-uniform cellular packaging of the stratum corneum and permeability barrier function of intact skin: a high-resolution confocal laser scanning microscopy study using highly deformable vesicles (Transferosomes). Br J Dermatol 1998: 138: 583-592.

[13] El Maghraby GM, Barry BW, Williams AC. Liposomes and skin: from drug delivery to model membranes. Eur J Pharm Sci 2008; 34:203-22.

[14] Barry BW. Transdermal drug delivery, in: Aulton's Pharmaceutics the design and manufacure of medicines (ed. ME Aulton), Churchill Livingstone Elsevier London 2007; 565597.

[15] Škalko N, Čajkovac M, Jalšenjak I. Liposomes with metronidazole for topical use: the choice of preparation method and vehicle, J Liposome Res 1998; 8:283-93. 
[16] Pavelić Ž, Škalko-Basnet N, Schubert R. Liposomal gels for vaginal drug delivery. Int J Pharm 2001; 219:139-49.

[17] Pavelić Ž, Škalko-Basnet N, Filipović-Grčić J, Martinac A, Jalšenjak I. Development and in vitro evaluation of a liposomal vaginal delivery system for acyclovir. J Control Release 2005; 106:34-43.

[18] Flaten GE, Palac Z, Engesland A, Filipović-Grčić J, Vanić Ž, Škalko-Basnet, N. In vitro skin models as a tool in optimization of drug formulation. Eur J Pharm Sci 2015 http://dx.doi.org/10.1016/j.ejps.2015.02.018

[19] Singh AV, A.S A, Gade WN, Vats T, Lenardi C, Milani, P. Nanomaterials: New generation therapeutics in wound healing and tissue repair. Current Nanoscience 2010; 6:577-86.

[20] Hurler J, Skalko-Basnet N. Advancements in burn therapy: Promise of nanomedicine, in Burns: Prevention, Causes and Treatment, (Eds. E.S. McLaughlin and A.O. Paterson) Nova Science Publishers, New York, pp. 39-63.

[21] DeLoiuse LA. Applications of nanotechnology in dermatology. J Invest Dermatol 2012; $132: 964-75$.

[22] Papakostas D, Rancan F, Sterry W, Blume-Peytavi U, Vogt A. Nanoparticles in dermatology. Arch Dermatol Res 2011; 303:533-50.

[23] Cevc G, Blume G. Lipid vesicles penetrate into intact skin owing to the transdermal osmotic gradients and hydration force. Biochim Biophys Acta 1992; 1104:226-32.

[24] Gillet A, Lecomte F, Hubert P, Ducat E, Evrard B, Piel G. Skin penetration behaviour of liposomes as a function of their composition. Eur J Pharm Biopharm 2011; 79:43-53.

[25] Verma DD, Verma S, Blume G, Fahr A. Liposomes increase skin penetration of entrapped and non-entrapped hydrophilic substances into human skin: a skin penetration and confocal laser scanning microscopy study. Eur J Pharm Biopharm 2003: 55:271-7. 
[26] Kristl J, Teskač K, Ahlin Grabnar P. Current view on nanosized solid lipid carriers for drug delivery to skin. J Biomed Nanotechnol 2010; 6:529-42.

[27] El Zaafarany GM, Awad GAS, Holayel SM, Mortada ND. Role of edge activators and surface charge in developing ultradeformable vesicles with enhanced skin delivery. Int J Pharm 2010; 397:164-72.

[28] Gonzalez-Rodriguez ML, Rabasco AM. Charged liposomes as carriers to enhance the permeation through the skin. Expert Opin Drug Deliv 2011; 8:857-71.

[29] Cortivo R, Vindigni V, Iacobellis L, Abatangelo, G, Pinton P, Zavan B. Nanoscale particle therapies for wounds and ulcers. Nanomedicine 2010; 5:641-56.

[30] Fenske DB, Cullis PR. Liposomal nanomedicine. Expert Opin Drug Deliv 2008; 5:24-44.

[31] Korting HC, Schäfer-Korting M. Carriers in the topical treatment of skin disease in Drug Delivery (ed. M Schäfer-Korting), Handbook of Experimental Pharmacology. Springer-Verlag Berlin 2010; 197:435-67.

[32] Sinico C, Fadda AM. Vesicular carriers for dermal drug delivery. Expert Opin Drug Deliv 2009; 6:813-25.

[33] Elsayed MMA, Abdallah OY, Nagger VF, Khalafallah NM. Lipid vesicles for skin delivery of drugs: Reviewing three decades of research. Int J Pharm 2007; 332:1-16.

[34] de Leeuw J, de Vijlder HC, Bjerring P, Neumann HA. Liposomes in dermatology today. J Eur Acad Dermatol Venereol 2009; 23:505-16.

[35] Mezei M, Gulasekharam V. Liposomes-a selective drug delivery system for the topical route of administration. Lotion dosage form. Life Sci 1980; 26:1473-7.

[36] Wohlrab W, Lasch J. Penetration kinetics of liposomal hydrocortisone in human skin. Dermatologica 1987; 174:18-22. 
[37] Wohlrab W, Lasch J. The effect of liposomal incorporation of topically applied hydrocortisone on its serum concentration and urinary excretion. Dermatol Monatsschr 1989; $175: 348-52$

[38] Gesztes A, Mezei M. Topical anesthesia of the skin by liposome-encapsulated tetracaine. Anesth Analg 1988; 67:1079-81.

[39] Foldvari M, Gesztes A, Mezei M. Dermal drug delivery by liposome encapsulation: clinical and electron microscopic studies. J Microencapsul 1990; 7:479-89.

[40] Christiansen K, Bjerring P, Troilius A. 5-ALA for photodynamic photorejuvenation-optimization of treatment regime based on normal-skin fluorescence measurements. Lasers Surg Med 2007; 39:302-10.

[41] Schäfer-Korting M, Korting HC, Ponce-Poschl E. Liposomal tretinoin for uncomplicated acne vulgaris. Clin Investig 1994; 72:1086-91.

[42] Körbel JN, Sebok B, Kerenyi M, Mahrle G. Enhancement of the antiparakeratotic potency of calcitriol and tacalcitol in liposomal preparations in the mouse tail test. Skin Pharmacol Appl Skin Physiol 2001; 14:291-5.

[43] Agarwal R, Saraswat A, Kaur I, Katare OP, Kumar B. A novel liposomal formulation of dithranol for psoriasis: preliminary results. J Dermatol 2002; 29:529-32.

[44] du Plessis J, Egbaria K, Ramachandran C, Weiner N. Topical delivery of liposomally encapsulated gamma-interferon. Antiviral Res 1992; 18:259-65.

[45] Lauer AC, Ramachandran C, Lieb LM, Niemiec S, Weiner .D. Targeted delivery to the pilosebaceous unit via liposomes. Adv Drug Deliver Rev 1996; 18:311-24.

[46] Tabbakhian M, Tavakoli N, Jaafari MR, Daneshamouz S. Enhancement of follicular delivery of finasteride by liposomes and niosomes 1 . In vitro permeation and in vivo deposition studies using hamster flank and ear models. Int J Pharm 2006; 323:1-10. 
[47] Jain B, Singh B, Katare OP, Vyas SP. Development and characterization of minoxidilloaded liposomal system for delivery to pilosebaceous units. J Liposome Res 2010; 20:105-14.

[48] Barry BW. Novel mechanisms and devices to enable successful transdermal drug delivery. Eur J Pharm Sci 2001; 14:101-14.

[49] El Maghraby GM, Williams AC, Barry BW. Can drug-bearing liposomes penetrate intact skin? J Pharm Pharmacol 2006; 58:415-29.

[50] Cevc G. Transfersomes, liposomes and other lipid suspensions on the skin: permeation enhancement, vesicle penetration, and transdermal drug delivery. Crit Rev Ther Drug Carrier Syst 1996; 13:257-388.

[51] Cevc G, Gebauer D, Stieber J, Schatzlein A, Blume G. Ultraflexible vesicles, Transfersomes, have an extremely low pore penetration resistance and transport therapeutic amounts of insulin across the intact mammalian skin. Biochim Biophys Acta 1998; 1368:201-15.

[52] Cevc G, Schatzlein A, Richardsen H. Ultradeformable lipid vesicles can penetrate the skin and other semi-permeable barriers unfragmented. Evidence from double label CLSM experiments and direct size measurements. Biochim Biophys Acta 2002; 1564:21-30.

[53] Honeywell-Nguyen PL, Wouter Groenink HW, de Graaff AM, Bouwstra JA. The in vivo transport of elastic vesicles into human skin: effects of occlusion, volume and duration of application. J Control Release 2003; 90:243-255.

[54] Cevc G, Blume G. New, highly efficient formulation of diclofenac for the topical, transdermal administration in ultradeformable drug carriers, Transfersomes. Biochim Biophys Acta 2001; 1514:191-205.

[55] Cevc G, Blume G, Schatzlein A. 1997. Transferosomes-mediated transdermal delivery improves the regio-specificity and biological activity of corticosteroids in vivo. J Control Release $1997 ; 45: 211-26$. 
[56] Cevc G. Transdermal drug delivery of insulin with ultradeformable carriers. Clin Pharmacokinet 2003; 42:461-74.

[57] Jain S, Sapre R, Tiwary AK, Jain NK. Proultraflexible lipid vesicles for effective transdermal delivery of levonorgestrel: development, characterization, and performance evaluation. AAPS PharmSciTech 2005; 6:E513-22.

[58] Jain S, Tiwary AK, Jain NK. Sustained and targeted delivery of an anti-HIV agent using elastic liposomal formulation: mechanism of action. Cur Drug Deliver 2006; 3:157-66.

[59] Benson HAE. Transferosomes for transdermal drug delivery. Expert Opin Drug Deliv 2006; 3:727-37.

[60] Darwhekar G, Jain DK, Choudhary A. Elastic liposomes for delivery of neomycin sulphate in deep skin infection. Asian J Pharm Sci 2012; 7:230-40.

[61] Pandit J, Garg M, Jain NK. Miconazole nitrate bearing ultraflexible liposomes for the treatment of fungal infection. J Liposome Res 2014; 24:163-9.

[62] Cadena PG, Pereira MA, Cordeiro RB, Cavalcanti IM, Barros Neto B, Pimentel Mdo C, Lima Filho JL, Silva VL, Santos-Magalhaes NS. Nanoencapsulation of quercetin and resveratrol into elastic liposomes. Biochim Biophys Acta 2013; 1828:309-16.

[63] Trotta M, Peira E, Carlotti ME, Gallarate M. Deformable liposomes for dermal administration of methotrexate. Int J Pharm 2004; 270:119-25.

[64] Srisuk P, Thongnopnua P, Raktanonchai U, Kanokpanont S. Physico-chemical characteristics of methotrexate-entrapped oleic acid-containing deformable liposomes for in vitro transepidermal delivery targeting psoriasis treatment. Int J Pharm 2012; 427:426-34.

[65] El Maghraby GM, Williams AC, Barry BW. Skin delivery of 5-fluorouracil from ultradeformable and standard liposomes in-vitro. J Pharm Pharmacol 2001; 53:1069-77. 
[66] Bahia APCO, Azevedo EG, Ferreira LAM, Frezard F. New insights into the mode of action of ultradeformable vesicles using calcein as hydrophilic fluorescent marker. Eur J Pharm Sci 2010; 39:90-6.

[67] Touitou E, Dayan N, Bergelson L, Godin B, Eliaz M. Ethosomes-novel carriers for enhanced delivery: characterization and skin penetration properties. J Control Release 2000; 65:403-18.

[68] Lopez-Pinto JM, Gonzalez-Rodriguez ML, Rabasco AM. Effect of cholesterol and ethanol on dermal delivery from DPPC liposomes. Int J Pharm 2005; 298:1-12.

[69] Touitou E, Godin B, Weiss C. Enhanced delivery of drugs into and across the skin by ethosomal carriers. Drug Dev Res 2000; 50:406-15.

[70] Touitou E, Godin B, Dayan N, Weiss C, Piliponsky A, Levi-Schaffer F. Intracellular delivery mediated by an ethosomal carrier. Biomaterials 2001; 22: 3053-9.

[71] Dayan N, Touitou E. Carriers for skin delivery of trihexyphenidyl $\mathrm{HCl}$ : ethosomes vs. liposomes. Biomaterials 2000; 21: 1879-85.

[72] Elsayed MM, Abdallah OY, Naggar VF, Khalafallah NM. Deformable liposomes and ethosomes: mechanism of enhanced skin delivery. Int J Pharm 2006; 322:60-66.

[73] Ainbinder D, Touitou E. Testosterone ethosomes for enhanced transdermal delivery. Drug Deliv 2005; 12:297-303.

[74] Lodzki M, Godin B, Rakou L, Mechoulam R, Gallily R, Touitou E. Cannabidioltransdermal delivery and anti-inflammatory effect in a murine model. J Control Release 2003; 93:377-87.

[75] Godin B, Touitou E. Mechanism of bacitracin permeation enhancement through the skin and cellular membranes from an ethosomal carrier. J Control Release 2004; 94:365-79.

[76] Godin B, Touitou E. Erythromycin ethosomal systems: physicochemiocal characterization and enhanced antibacterial activity. Curr Drug Deliv 2005; 2:269-75. 
[77] Godin B, Touitou E, Rubinstein E, Athamna A, Athamna M. A new approach for treatment of deep skin infections by an ethosomal antibiotic preparation: an in vivo study. $\mathrm{J}$ Antimicrob Chemother 2005; 55:989-994.

[78] Meng S, Chen Z, Yang L, Zhang W, Liu D, Guo J, Guan Y, Li J. Enhanced transdermal bioavailability of testosterone propionate via surfactant-modified ethosomes. Int J Nanomedicine $2013 ; 8: 3051-60$.

[79] Dubey V, Mishra D, Jain NK. Melatonin loaded ethanolic liposomes: physicochemical characterization and enhanced transdermal delivery. Eur J Pharm Biopharm 2007; 67:398-405.

[80] Ghanbarzadeh S, Arami S. Enhanced transdermal delivery of diclofenac sodium via conventional liposomes, ethosomes, and transferosomes. BioMed Res Int 2013; 2013:1-7.

[81] Chourasia MK, Kang L, Chan SY. Nanosized ethosomes bearing ketoprofen for improved transdermal delivery. Results in Pharma Sciences 2011; 1:60-7.

[82] Paolino D, Lucania G, Mardente D, Alhaique F, Fresta M. Ethosomes for skin delivery of ammonium glycyrrhizinate: in vitro percutaneous permeation through human skin and in vivo anti-inflammatory activity on human volunteers. J Control Release 2005; 106:99-110.

[83] Thapa B, Pepić I, Vanić Ž, Basnet P, Škalko-Basnet N. Topical delivery system for phytochemicals: Capsaicin and Capsicum tincture. J Pharm Drug Develop 2013; 1 (2)

[84] Zhu X, Li F, Peng X, Zeng K. Formulation and evaluation of lidocaine base ethosomes for transdermal delivery. Anesth Analg 2013; 117:352-357.

[85] Horwitz E, Pisanty S, Czerninski R, Helser M, Eliav E, Touitou E. A clinical evaluation of a novel liposomal carrier for acyclovir in the topical treatment of recurrent herpes labialis. Oral Surg Oral Med Oral Pathol Oral Radio Endod 1999; 87:700-5.

[86] Verma DD, Fahr A. Synergistic penetration enhancement effect of ethanol and phospholipids on the topical delivery of cyclosporin A. J Control Release 2004; 97:55-66. 
[87] Dubey V, Mishra D, Dutta T, Nahar M, Saraf DK, Jain NK. Dermal and transdermal delivery of an anti-psoriatic agent via ethanolic liposomes. J Control Release 2007a; 123:148-54.

[88] Cevc G, Mazgareanu S, Rother M. Preclinical characterisation of NSAIDs in ultradeformable carriers or conventional topical gels. Int J Pharm 2008. 360, 29-39.

[89] Meidan VM, Touitou E. Treatments for androgenetic alopecia and alopecia areata: current options and future prospects. Drugs 2001; 61:53-69.

[90] Goindi S, Dhatt B, Kaur A. Ethosomes-based topical delivery system of antihistaminic drug for treatment of skin allergies. J Microencapsul 2014; 31:716-24.

[91] Li G, Fan Y, Fan C, Li X, Wang X, Li M, Liu Y. Tacrolimus-loaded ethosomes: physicochemical characterization and in vivo evaluation. Eur J Pharm Biopharm 2012.; 82:49-57. [92] Zhang Y-T, Shen L-N, Zhao J-H, Feng N-P. Evaluation of psoralen ethosomes for topical delivery in rats by using in vivo microdialysis. Int J Nanomedicine 2014; 9: 669-78.

[93] Elsayed MMA, Abdallah OY, Naggar VF, Khalafallah NM. PG-liposomes: novel lipid vesicles for skin delivery of drugs. J Pharm Pharmacol 2007; 59:1447-50.

[94] Manconi M, Mura S, Sinico C, Fadda AM, Vila AO, Molina F. Development and characterization of liposomes containing glycols as carriers for diclofenac. Colloid Surface A $2009 ; 342: 53-8$.

[95] Mura S, Manconi M, Sinico C, Valenti D, Fadda AM. Penetration enhancer-containing vesicles (PEVs) as carriers for cutaneous delivery of minoxidil. Int J Pharm 2009; 380:72-9.

[96] Dragicevic-Curic N, Scheglmann D, Albrecht V, Fahr A. Temoporfin-loaded invasomes: development, characterization and in vitro skin penetration studies. J Control Release 2008; 127:59-69.

[97] Kikuchi H, Yamauchi H, Hirota S. A polyol dilution method for mass production of liposomes, J Liposome Res 1994; 4:71-91. 
[98] Pavelić Ž, Škalko-Basnet N, Jalšenjak I. Liposomes containing drugs for treatment of vaginal infections. Eur J Pharm Sci 1999; 8:345-51.

[99] Vanić Ž, Hurler J, Ferderber K, Golja Gašparović P, Škalko-Basnet N, Filipović-Grčić J. Novel vaginal drug delivery system: deformable propylene glycol liposomes-in-hydrogel. J Liposome Res 2014; 24:27-36.

[100] Palac Z, Engesland A, Flaten GE, Škalko-Basnet N, Filipović-Grčić J, Vanić Ž. Liposomes for (trans)dermal drug delivery: the skin-PVPA as a novel in vitro stratum corneum model in formulation development. J Liposome Res 2014; 24:313-22.

[101] Manconi M, Caddeo C, Sinico C, Valenti D, Mostallino MC, Biggio G, Fadda AM. Ex vivo skin delivery of diclofenac by transcutol containing liposomes and suggested mechanism of vesicle-skin interaction. Eur J Pharm Biopharm 2011:78:27-35.

[102] Zhao Y-Z, Lu C-T, Zhang Y, Xiao J, Zhao Y-P, Tian J-L, Xu Y-Y, Feng Z-G, Xu C-Y. Selection of highly efficient transdermal lipid vesicle for curcumin skin delivery. Int $\mathrm{J}$ Pharm $2013 ; 454: 302-9$.

[103] Chessa M, Caddeo C, Valenti D, Manconi M, Sinico C, Fadda AM. Effect of penetration enhancer containing vesicles on the percutaneous delivery of quercetin through new born pig skin. Pharmaceutics 2011; 3, 497-509.

[104] Mura S, Manconi M, Valenti D, Sinico C, Vila AO, Fadda AM. Transcutol containing vesicles for topical delivery of minoxidil. J Drug Target 2011; 19:189-96.

[105] Wang JP, Guo F, Ma M, Li N, Tan FP. Development of ketoconazole nanovesicular system using 1,2-hexanediol and 1,4-cyclohexanediol for dermal targeting delivery: physicochemical characterization and in vitro/in vivo evaluation. J Nanopart Res 2014; 16:2505 
[106] Dragicevic-Curic N, Scheglmann D, Albrecht V, Fahr A. Development of different temoporfin-loaded invasomes-novel nanocarriers of temoporfin: characterization, stability and in vitro skin penetration studies. Colloid Surfaces B, Biointerfaces 2009; 70:198-206.

[107] Hiruta Y, Hattori Y, Kawano K, Obata Y, Maitani Y. Novel ultra-deformable vesicles entrapped with bleomycin and enhanced to penetrate rat skin. J Control Release 2006; 113:14654.

[108] Yarosh D, Bucana C, Cox P, Alas L, Kibitel J, Kripke M. Localization of liposomes containing a DNA repair enzyme in murine skin. J Invest Dematol 1994; 103:461-8.

[109] Yarosh DB. Liposomes in investigative dermatology. Photodermatol Photoimmunol Photomed 2001; 17:203-12.

[110] Yarosh D, Klein J, O'Connor A, Hawk J, Rafal E, Wolf P. Effect of topically applied T4 endonuclease $\mathrm{V}$ in liposomes on skin cancer in xeroderma pigmentosum: a randomised study. Xeroderma Pigmentosum Study Group. Lancet 2001; 357:926-9.

[111] Wolf P, Maier H, Mullegger RR, Chadwick CA, Hofmann-Wellenhof R, Soyer HP, Hofer A, Smolle J, Horn M, Cerroni L, Yarosh D, Klein J, Bucana C, Dunner K Jr, Potten CS, Honigsmann H, Kerl H, Kripke ML. Topical treatment with liposomes containing T4 endonuclease $\mathrm{V}$ protects human skin in vivo from ultraviolet-induced upregulation of interleukin10 and tumor necrosis factor-alpha. J Invest Dermatol 2000; 114:149-156.

[112] Chang H-I, Yeh M-K. Clinical development of liposome-based drugs: formulation, characterization, and therapeutic efficacy. Int J Nanomedicine 2012; 7:49-60.

[113] Foldavari M, Badea I, Wettig S, Baboolak D, Kumar P, Creagh AL, Hayes CA. Topical delivery of interferon alpha by biphasic vesicles: Evidence for a novel nanopathway across the stratum corneum. Mol Pharm 2010; 7:751-62. 
[114] King MJ, Badea I, Solomon J, Kumar P, Gaspar KJ, Foldvari M. Transdermal delivery of insulin from a novel biphasic lipid system in diabetic rats. Diabetes Techol Therap 2002; 4:47988.

[115] King MJ, Michel D, Foldvari M. Evidence for lymphatic transport of insulin by topically applied biphasic vesicles. J Pharm Pharmaol 2003; 55:1339-44.

[116] King M, Kumar P, Michel D, Batta R, Foldvari M. In vivo sustained dermal delivery and pharmacokinetics of interfereon alpha in biphasic vesicles after topical application. Eur J Pharm Biopharm 2013; 84:532-9.

[117] Foldavari M, Badea I, Kumar P, Wettig S, Batta R, King MJ, He Z, Yeboah E, Gasper K, Hull P, Shear NH. Biphasic vesicles for topical delivery of interferon alpha in human volunteers and treatment of patients with human papillomavirus infections. Curr Drug Deliv 2011; 8:307-19. [118] Zhang L, Pornpattananangku D, Hu CM, Huang CM. Development of nanoparticles for antimicrobial drug delivery. Curr Med Chem 2010; 17:585-94.

[119] Puglia C, Bonina F. Lipid nanoparticles as novel delivery systems for cosmetics and dermal pharmaceuticals. Expert Opin Drug Deliv 2012; 9:429-441.

[120] Pardeike J, Hommoss A, Müller RH. Lipid nanoparticles (SLN, NLC) in cosmetic and pharmaceutical dermal products. Int J Pharm 2009; 366:170-84.

[121]Ahlin P, Kristl J, Šentjurc M, Štrancar J, Pečar S. 2000. Influence of spin probe structure on its distribution in SLN dispersions. Int J Pharm 2000; 196:241-4.

[122] Ahlin P, Kristl J, Pečar S, Štrancar J, Šentjurc M. The effect of lipophilicity of spin-labeled compounds on their distribution in solid lipid nanoparticle dispersions studied by electron paramagnetic resonance. J Pharm Sci 2003; 92:58-66.

[123] Müller RH, Mäder K, Gohla S. Solid lipid nanoparticles (SLN) for controlled drug delivery - a review of the state of the art. Eur J Pharm Biopharm 2000; 50:161-77. 
[124] Jensen LB, Magnussson E, Gunnarsson L, Vermehren C, Nielsen HM, Petersson K. Corticosteroid solubility and lipid polarity control release from solid lipid nanoparticles. Int $\mathbf{J}$ Pharm 2010; 390:53-60.

[125] Jensen LB, Petersson K, Nielsen HM. In vitro penetration properties of solid lipid nanoparticles in intact and barrier-impaired skin. Eur J Pharm Biopharm 2011; 79:68-75.

[126] Teskač K, Kristl J. The evidence for solid lipid nanoparticles mediated cell uptake of resveratrol. Int J Pharm 2010; 39:61-9.

[127] Schäfer-Korting M, Mehnert W, Korting H-C. Lipid nanoparticles for improved topical application of drugs for skin diseases. Adv Drug Deliver Rev 2007; 59:427-43.

[128] Vaghasiya H, Kumar A, Sawant K. Development of solid lipid nanoparticles based controlled release system for topical delivery of terbinafine hydrochloride. Eur J Pharm Sci 2013; 49:311-22.

[129] Sanna V, Gavini E, Cossu M, Rassu G, Giunchedi P. Solid lipid nanoparticles (SLN) as carriers for topical delivery of econazole nitrate: in-vitro characterization, ex-vivo and in-vivo studies. J Pharm Pharmacol 2007; 59:1057-64.

[130] Zhang J, Smith E. Percutaneous permeation of betamethasone 17-valerate incorporated in lipid nanoparticles. J Pharm Sci 2011; 100:896-903.

[131] Kristl J, Teskač K., Caddeo C, Abramović Z, Šentjurc M. Improvements of cellular stress response on resveratrol in liposomes. Eur J Pharm Biopharm 2009; 73:253-9.

[132] Müller RH, Petersen RD, Hommoss A, Pardeike J. Nanostructured lipid carriers (NLC) in cosmetic dermal products. Adv Drug Deliv Rev 2007; 59:522-30.

[133] Zhang XY, Liu JP, Qiao H, Liu H, Ni JM, Zhang WL, Shi YB. Formulation optimization of dihydroartemisinin nanostructured lipid carrier using response surface methodology. Powder Technol 2010; 197:120-28. 
[134] Joshi M, Patravale V. Nanostructured lipid carrier (NLC) based gel of celecoxib. Int J Pharm 2008; 346:124-32.

[135] Gomes MJ, Martins S, Ferreira D, Segundo M., Reis S. Lipid nanoparticles for topical and transdermal application for alopecia treatment: development, physicochemical characterization, and in vitro release and penetration studies. Int J Nanomedicine 2014; 9:1231-42.

[136] Agrawal Y, Petkar KC, Sawant KK. Development, evaluation and clinical studies of acitretin loaded nanostructured lipid carriers for topical treatment of psoriasis. Int J Pharm 2010; 401:93-102.

[137] Lin YK, Huang ZR, Zhuo RZ, Fang JY. Combination of calcipotriol and methotrexate in nanostructured lipid carriers for topical delivery. Int J Nanomedicine 2010; 5:117-28.

[138] Pople PV, Singh KK. Development and evaluation of colloidal modified nanolipid carrier: application to topical delivery of tacrolimus. Eur J Pharm Biopharm 2011; 79:82-94.

[139] Pople PV, Singh KK. Development and evaluation of colloidal modified nanolipid carrier: application to topical delivery of tacrolimus, Part II--in vivo assessment, drug targeting, efficacy, and safety in treatment for atopic dermatitis. Eur J Pharm Biopharm 2013; 84:72-83.

[140] Han F, Li S, Yin R, Shi X, Jia Q. Investigation of nanostructured lipid carriers for transdermal delivery of flurbiprofen. Drug Dev Ind Pharm 2008; 34:453-8.

[141] Ricci M, Puglia C, Bonina F, Di Giovanni C, Giovagnoli S, Rossi C. Evaluation of indomethacin percutaneous absorption from nanostructured lipid carriers (NLC): in vitro and in vivo studies. J Pharm Sci 2005; 94:1149-59.

[142] Santos P, Watkinson AC, Hadgraft J, Lane ME. Application of microemulsions in dermal and transdermal drug delivery. Skin Pharmacol Physiol 2008; 21:246-59. 
[143] Shakeel F, Shafiq S, Haq N, Alanazi FK, Alsarra IA. Nanoemulsions as potential vehicles fro transdermal and dermal delivery of hydrophobic compounds: an overview. Expert Opin Drug Deliv 201; 9:953-74.

[144] Abramović Z, Šuštaršič U, Teskač K, Šentjurc M, Kristl J. Influence of nanosized delivery systems with benzyl nicotinate and penetration enhancers on skin oxygenation. Int J Pharm 2008; 359:220-27.

[145] Schwarz JC, Klang V, Karall S, Mahrhauser D, Resch GP, Valenta C. Optimization of multiple W/O/W nanoemulsions for dermal delivery of acyclovir. Int J Pharm 2012; 435:69-75.

[146] Zarif L. Drug Delivery by lipid cochleates. Methods Enzymol. 2005; 391:314-29.

[147] Landge A, Pawar A, Shaikh K. Investigation of cochleates as carriers for topical drug delivery. Int J Pharm Pharm Sci 2013; 5:314-20.

[148] Kong HH, Segre JA. Skin microbiome: Looking back to move forward. J Invest Dermatol $2012 ; 132: 933-9$.

[149] Yang D, Pornpattananangkul D, Nakatsuji T, Chan M, Carson D, Huang C-M, Zhang L. The antimicrobial activity of liposomal lauric acids against Propionibacterium acnes. Biomaterials 2009; 30:6035-40.

[150] Martin JM, Zenilman, JM, Lazarus GS. Molecular microbiology: New dimensions for cutaneous biology and wound healing. J Invest Dermatol 2010; 130:38-48.

[151] Lynch AS, Abbanat D. New antibiotic agents and approaches to treat biofilm-associated infections. Expert Opin Ther Patents 2010; 20: 1373-87.

[152] Basnet P, Škalko-Basnet N. Nanodelivery systems for improved topical antimicrobial therapy, Curr Pharm Design 2013; 19:7237-43.

[153] Yang W, Wiederhold P, Williams III RO. Drug delivery strategies for improved azole antifungal action. Expert Opin Drug Deliv 2008; 5:1199-216. 
[154] Huh AJ, Kwon YJ. "Nanoantibiotics": A new paradigm for treating infectious diseases using nanomaterials in the antibiotics resistant era. J Control Release 2011; 156:128-45.

[155] Naeff R. Feasibility of topical liposome drugs produced on an industrial scale. Adv Drug Deliver Rev 1996; 18:343-7.

[156] Sanderson NM, Jones, MN. Encapsulation of vancomycin and gentamicin within cationic liposomes for inhibition of growth of Staphylococcus epidermidis. J Drug Targeting 1996; 4:1819.

[157] Kim H-J, Jones MN. The delivery of benzyl penicillin to Staphylococcus aureus biofilms by use of liposomes. J Liposome Res 2004; 14:123-39.

[158] Vanić Ž, Hafner A, Bego M., Škalko-Basnet N. Characterization of various deformable liposomes with metronidazole. Drug Dev Ind Pharm 2013; 39:481-8.

[159] Vogt PM, Reimer K, Hauser J, Roßbach O, Steinau HU, Bosse B, Muller S, Schmidt T, Fleischer W. PVP-iodine in hydrosomes and hydrogel - A novel concept in wound therapy leads to enhanced epithelialisation and reduced loss of skin grafts. Burns 2006; 32:698-705.

[160] Song CK, Balakrishnan P, Shim CK, Chung SJ, Chong S, Kim DD. A novel vesicular carrier, transethosome, for enhanced skin delivery of voriconazole: characterization and in vitro/in vivo evaluation. Colloids Surf B Biointerfaces 2012; 92:299-304.

[161] Elmoslemany RM, Abdallah OY, El-Khordagui LK, Khalafallah NM. Propylene glycol liposomes as a topical delivery system for miconazole nitrate: comparison with conventional liposomes. AAPS PharmSciTech 2012; 13:723-31.

[162] Souto EB, Wissing SA, Barbosa CM, Müller RH. Development of a controlled release formulation based on SLN and NLC for topical clotrimazole delivery. Int J Pharm 2004; 278:717. 
[163] Castro GA, Ferreira LAM. Novel vesicular and particulate drug delivery systems for topical treatment of acne. Expert Opin Drug Deliv 2008; 5:665-679.

[164] Date AA, Naik B, Nagarsenker MS. Novel drug delivery systems: potential in improving topical delivery of antiacne agents. Skin Pharmacol Physiol 2006; 19:2-16.

[165] Škalko N, Čajkovac,M, Jalšenjak I. Liposomes with clindamycin hydrochloride in the therapy of Acne vulgaris. Int J Pharm 1992; 85:97-101.

[166] Honzak L, Šentjurc M. Development of liposome encapsulated clindamycin for treatment of acne vulgaris. Pflug Arch Eur J Phy 2000; 440:R44-R45.

[167] Patel VB, Mishra AN, Marfatia YS. Preparation and comparative clinical evaluation of liposomal gel of benzoyl peroxide for acne. Drug Dev Ind Pharm 2001; 27:863-9.

[168] Mandawgade SD, Patravale VB. Development of SLNs from natural lipids: application to topical delivery of tretinoin. Int J Pharm 2008; 363:132-8.

[169] Štecová J, Mehnert W, Blaschke T, Kleuser B, Sivaramakrishnan R, Zouboulis CC, Seltmann H., Korting HC, Kramer KD, Schäfer-Korting M. Cyproterone acetate loading to lipid nanoparticles for topical acne treatment: particle characterisation and skin uptake. Pharm Res $2007 ; 24: 991-1000$

[170] Kaur N, Puri R, Jain SK. Drug-cyclodextrin-vesicles dual carrier approach for skin targeting of anti-acne agent. AAPS PharmSciTech 2010; 11:528-37.

[171] Lau KG, Hattori Y, Chopra S, O'Toole EA, Storey A, Nagai T, Maitani Y. Ultradeformable liposomes containing bleomycin: in vitro stability and toxicity on human cutaneous keratinocyte cell lines. Int J Pharm 2005; 300:4-12.

[172] Paolino D, Celia C, Trapasso E, Cilurzo F, Fresta M. Paclitaxel-loaded ethosomes(R): potential treatment of squamous cell carcinoma, a malignant transformation of actinic keratoses. Eur J Pharm Biopharm 2012; 81:102-12. 
[173] Branski LK, Gauglitz GG, Herndon DN, Jeschke MG. A review of gene and stem cell therapy in cutaneous wound healing. Burns 2009; 35:171-80.

[174] Jeschke MG, Herndon DN, Baer W, Barrow RE, Jauch KW. Possibilities of non-viral gene transfer to improve cutaneous wound healing. Curr Gene Ther 2001; 1:267-78.

[175] Jeschke MG, Richter G, Höfstädter F, Herndon DN, Perez-Polo J-R, Jauch KW. Non-viral liposomal keratinocyte growth factor (KGF) cDNA gene transfer. Gene Ther 2002; 9:1065-74.

[176] Kim A, Lee EH, Choi S-H, Kim C-K. In vitro and in vivo transfection efficiency of novel ultradeformable cationic liposome. Biomater 2004; 25:305-313.

[177] Lee EH, Kim A, Oh Y-K, Kim C-K. Effect of edge activators on the formation and transfection efficiency of ultradeformable liposomes. Biomater 2005; 26:205-210.

[178] Babiuk S, Baca-Estrada ME, Pontarollo R, Foldavari M. Topical delivery of plasmid DNA using biphasic lipid vesicles (Biphasix). J Pharm Pharmacol 2002; 54:1609-14.

[179] Bal SM, Ding Z, van Riet E, Jiskoot W, Bouwstra JA. Advances in transcutaneous vaccine delivery: Do all ways lead to Rome? J Control Release 2010; 148:266-282.

[180] Baca-Estrada ME, Foldavari M, Babiuk SL, Babiuk LA. Vaccine delivery: lipid-based delivery systems. J Biotechnol 2000a; 83:91-104.

[181] Combadiére B, Mahé B. Particle-based vaccines for transcutaneous vaccination. Comp Immunol Microb Infect Dis 2008; 31:293-315.

[182] Paul A, Cevc G, Bachhawat BR. Transdermal immunization with large proteins by means of ultradeformable drug carriers. Eur J Immunol 1995; 25:3521-4.

[183] Paul A, Cevc G, Bachhawat BR. Transdermal immunization with an integral membrane component, gap junction protein, by means of untradeformable drug carriers, transferosomes. Vaccine 1998; 16:188-95. 
[184] Gupta PN, Mishra V, Rawat A, Dubey P, Mahor S, Jain S, Chatterji DP, Vyas SP. Noninvasive vaccine delivery in transferosomes, niosomes and liposomes: a comparative study. Int $\mathbf{J}$ Pharm 2005; 293:73-82.

[185] Gupta PN, Mishra V, Singh P, Rawat A, Dubey P, Mahor S, Vyas SP. Tetanus toxoidloaded transfersomes for topical immunization. J Pharm. Pharmacol 2005; 57:295-301.

[186] Mishra D, Dubey V, Asthana A, Saraf DK, Jain NK. Elastic liposomes mediated transcutaneous immunization against Hepatitis B. Vaccine 2006; 24:4847-4855.

[187] Mishra D, Mishra PK, Dubey V, Nahar M, Dabadghao S, Jain NK. Systemic and mucosal immune response induced by transcutaneous immunization using Hepatitis B surface antigenloaded modified liposomes. Eur J Pharm Sci 2008; 33:424-33.

[188] Chopra A, Cevc G. Non-invasive, epicutaneous immunization with toxoid in deformable vesicles protects mice against tetanus, chiefly owing to a Th2 response. Eur J Pharm Sci 2014; 56:55-64.

[189] Baca-Estrada ME, Foldavari M, Ewen C, Badea I, Babiuk LA. Effects of IL-12 on immune responses induced by transcutaneous immunization with antigens formulated in a novel lipidbased biphasic delivery system. Vaccine 2000; 18:1847-54.

[190] Nasir A. Nanotechnology and dermatology: Part II-risks of nanotechnology. Clin Dermatol $2010 ; 28: 581-8$.

[191] Teskač Plajnšek, K, Pajk, S, Govedarica, B, Pečer, S, Srčič, S, Kristl, J. A novel fluorescent probe for more effective monitoring of nanosized drug delivery systems within the cells. Int $\mathbf{J}$ Pharm 2011; 416:384-93.

[192] Kneer W, Rother I, Rother M, Seidel E. A multi-dose, open-label, safety, compliance, and usage evaluation study of epicutaneously applied Diractin ${ }^{\circledR}$ (ketoprofen in Transferosome ${ }^{\circledR}$ in joint/musculoskeletal pain or soft tissue inflammation. Curr Drug Safety 2009; 4:5-10. 
[193] Mak WC, Richter H, Patzelt A, Sterry W, Lai KK, Renneberg R, Lademan J. Drug delivery into the skin by degradable particles. Eur J Pharm Biopharm 2011; 79:23-7.

[194] Mak WC, Patzel A, Richter H, Renneberg R, Lai KK, Rühl E, Sterry W, Lademann J. Triggering of drug release of particles in hair follicles. J Control Release 2012; 160:509-14.

[195] Jung S, Patzelt A, Otberg N, Thiede G, Sterry W, Lademann J. Strategy of topical vaccination with nanoparticles. J Biomed Opt 2009; 14:021001.

[196] Sand M, Bechara FG, Sand D, Altmeyer P, Hoffmann K. A randomized, controlled, double-blind study evaluating melanin-encapsulating liposomes as a chromophore for laser hair removal of blond, white and grey hair. Ann Plast Surg 2007; 58: 551-554.

[197] Kaur L, Jain SK, Manhas RK, Sharma D. Nanoethosomal formulation for skin targeting of amphotericin B: an in vitro and in vivo assessment. J Liposome Res 2014; DOI:10.3109/08982104.2014.995670

[198] Hussain A, Samad A, Singh SK, Ahsan MN, Haque MW, Faruk A, Ahmed FJ. Nanoemulsion gel-based topical delivery of an antifungal drug: in vitro activity and in vivo evaluation. Drug Deliv 2014; doi:10.3109/10717544.2014.933284

[199] Li C, Zhang X, Huang X, Wang X, Liao G, Chen Z. Preparation and characterization of flexible nanoliposomes loaded with daptomycin, a novel antibiotic, for topical skin therapy. Int J Nanomed 2013; 8:1285-92.

[200] Touitou E, Godin B. Vesicular carriers for enhanced delivery through the skin in Touitou E, Godin B, Barry BW. (Eds) Enhancement in Drug Delivery, CRC Press, Boca Raton, pp 255$301,2006$.

[201] Vogt PM, Hauser J, Rossbach O, Bosse B, Fleischer W, Steinau HU, Reimer K. Polyvinyl pyrrolidone-iodine liposome hydrogel improves epithelialization by combining moisture and antisepis. A new concept in wound therapy. Wound Repair Regen 2001; 9:116-22. 
[202] Homann HH, Rosbach O, Moll W, Vogt PM, Germann G, Hopp M, Langer-Brauburger B, Reimer K, Steinau HU. A liposome hydrogel with polyvinyl-pyrrolidone iodine in the local treatment of partial-thickness burn wounds. Ann Plast Surg 2007; 59:423-7.

[203] de Leeuw J, van der Beek N, Maierhofer G, Neugebauer WD. A case study to evaluate the treatment of vitiligo with khellin encapsulated in L-phenylalanin stabilized phosphatidylcholine liposomes in combination with ultraviolet light therapy. Eur J Dermatol 2003; 13:474-7.

[204] Gruber DM, Sator MO, Joura EA, Kokoschka EM, Heinze G, Huber JC. Topical cyproterone acetate treatment in women with acne: a placebo-controlled trial. Arch Dermatol $1998 ; 134: 459-63$.

[205] Shah KA, Date AA, Joshi MD, Patravale VB. Solid lipid nanoparticles (SLN) of tretinoin: potential in topical delivery. Int J Pharm 2007; 345:163-71.

[206] de Leeuw J, van der Beek N, Bjerring P, Neumann HA. Photodynamic therapy of acne vulgaris using 5-aminolevulinic acid $0.5 \%$ liposomal spray and intense pulsed light in combination with topical keratolytic agents. J Eur Acad Dermatol Venereol 2010; 24:460-9.

[207] Cevc G, Blume G. Biological activity and characteristics of triamcinolone-acetonide formulated with the self-regulating drug carriers, Transfersomes. Biochim Biophys Acta 2003; $1614: 156-64$.

[208] Cevc G, Blume G. Hydrocortisone and dexamethasone in very deformable drug carriers have increased biological potency, prolonged effect, and reduced therapeutic dosage. Biochim Biophys Acta 2004; 1663:61-73.

[209] Fontana MC, Rezer JFP, Coradini K, Leal DBR, Beck RCR. Improved efficacy in the treatment of contact dermatitis in rats by a dermatological nanomedicine containing clobetasol propionate. Eur J Pharm Biopharm 2011; 79:241-9. 
[210] Kalariya M, Padhi BK, Chougule M, Misra A. Clobetasol propionate solid lipid nanoparticles cream for effective treatment of eczema: formulation and clinical implications. Indian J Exp Biol 2005; 43:233-40.

[211] Raza K, Singh B, Lohan S, Sharma G, Negi P, Yachha Y, Katare OP. Nano-lipoidal carriers of tretinoin with enhanced percutaneous absorption, photostability, biocompatibility and anti-psoriatic activity. Int J Pharm 2013; 456:65-72.

[212] Dirschka T, Radny P, Dominicus R, Mensing H, Bruning H, Jenne L, Karl L, Sebastian M, Oster-Schmidt C, Klovekorn W, Reinhold U, Tanner M, Grone D, Deichmann M, Simon M, Hubinger F, Hofbauer G, Krahn-Senftleben G, Borrosch F, Reich K, Berking C, Wolf P, Lehmann P, Moers-Carpi M, Honigsmann H, Wernicke-Panten K, Helwig C, Foguet M, Schmitz B, Lubbert H, Szeimies RM. Photodynamic therapy with BF-200 ALA for the treatment of actinic keratosis: results of a multicentre, randomized, observer-blind phase III study in comparison with a registered methyl-5-aminolaevulinate cream and placebo. Br J Dermatol 2012; 166:137-46.

[213] Khandavilli S, Panchagnula R. Nanoemulsions as versatile formulations for paclitaxel delivery: peroral and dermal delivery studies in rats. J Invest Dermatol 2007; 127:154-62.

[214] Guo J, Ping Q, Sun G, Jiao C. Lecithin vesicular carriers for transdermal delivery of cyclosporin A. Int J Pharm 2000; 194:201-7.

[215] Puri R, Jain S. Ethogel topical formulation for increasing the local bioavailability of 5fluorouracil: a mechanistic study. Anticancer Drugs 2012; 23:923-34.

[216] Planas ME, Gonzalez P, Rodriguez L, Sanchez S, Cevc G. Noninvasive percutaneous induction of topical analgesia by a new type of drug carrier, and prolongation of local pain insensitivity by anesthetic liposomes. Anesth Analg 1992; 75:615-21. 
[217] Jain SK, Chourasia MK, Masuriha R, Soni V, Jain A, Jain NK, Gupta Y. Solid lipid nanoparticles bearing flurbiprofen for transdermal delivery. Drug Deliv 2005; 12:207-15.

[218] Sakeena MHF, Yam MF, Elrashid SM, Munavvar AS, Azmin MN. Anti-inflammatory and analgesic effects of ketoprofen in palm oil esters nanoemulsion. J Oleo Sci 2010; 59:667-71.

[219] Gorski G, Szopinski P, Michalak J, Marianowska A, Borkowski M, Geremek M, Trochimczuk M, Brotanek J, Sarnik S, Semenka J, Wilkowski D, Noszczyk W. Liposomal heparin spray: a new formula in adjunctive treatment of superficial venous thrombosis. Angiology 2005; 56:9-17. 


\section{Figure and Table legends:}

Figure 1. Schematic drawings of different types of liposomes commonly studied in the skin delivery of drugs: conventional liposome (A), deformable liposome (B), ethosome (C), penetration enhancer embodying liposome (D, e.g. propylene glycol liposome).

Figure 2. Schematic drawings of solid lipid nanoparticle (SLN, A) having more or less perfect crystalline structure (similar to brick wall) and nanostructured lipid carrier (NLC, B) consisting of a crystalline matrix with many imperfections leading to improved loading efficiency and stability.

Table 1. Potentials and limitations of different (phospho)lipid vesicles for skin delivery of drugs

Table 2. Overview of selected clinical and in vivo studies investigating efficiency of lipid-based nanosystems for skin delivery of drugs.

Table 3. Examples of registered lipid-based nanosystems for (trans)dermal drug delivery. 